\title{
The implication of spatial interpolated climate data on biophysical modelling in agricultural systems
}

Table 3 Statistical tests of the differences between the APSIM outputs resulting from observed and interpolated climate variables and the differences between the interpolated spatial APSIM-output maps resulting from the observed climate variables, interpolated climate variables and the 5-km gridded climate variables. The acronyms are shown in Table 4.

\begin{tabular}{|c|c|c|c|c|c|c|c|c|c|c|c|c|}
\hline Data source (no) & $\begin{array}{l}\mathrm{RO} \\
(\mathrm{mm})\end{array}$ & $\begin{array}{l}\begin{array}{l}\mathrm{DD} \\
(\mathrm{mm})\end{array} \\
\end{array}$ & $\begin{array}{l}\text { CES } \\
(\mathrm{mm})\end{array}$ & $\begin{array}{l}\text { WU } \\
(\mathrm{mm})\end{array}$ & $\begin{array}{l}\text { NU } \\
\left(\mathrm{kg} \mathrm{ha}^{-1}\right)\end{array}$ & $\begin{array}{l}\text { SD } \\
\text { (days) }\end{array}$ & $\begin{array}{l}\text { STF } \\
\text { (days) }\end{array}$ & $\begin{array}{l}\begin{array}{l}\text { FTH } \\
\text { (days) }\end{array} \\
\text { (d) }\end{array}$ & $\begin{array}{l}\text { CD } \\
\text { (days) }\end{array}$ & $\begin{array}{l}\text { HD } \\
\text { (days) }\end{array}$ & $\begin{array}{l}\mathrm{BM} \\
\left(\mathrm{kg} \mathrm{ha}^{-1}\right)\end{array}$ & $\begin{array}{l}\text { CY } \\
\left(\mathrm{kg} \mathrm{ha}^{-1}\right)\end{array}$ \\
\hline \multicolumn{13}{|c|}{ MAE } \\
\hline SILO vs NSG (370) & 0.00 & -1.69 & -0.84 & -0.19 & -0.69 & 0.00 & 0.01 & 0.01 & 0.01 & 0.01 & -4.64 & -6.80 \\
\hline $\mathrm{I}_{\text {SILO }}$ vs $\mathrm{I}_{\mathrm{NSG}}(4741)$ & -0.28 & -1.86 & -0.97 & -0.12 & -0.68 & 0.42 & -0.63 & -0.01 & -0.63 & -0.21 & -21.08 & -2.33 \\
\hline $\mathrm{I}_{\mathrm{NSG}}$ vs $\mathrm{I}_{\mathrm{GC}}(4741)$ & 0.18 & -0.31 & -0.63 & 0.31 & 0.67 & -0.23 & -0.06 & 0.04 & 0.05 & -0.21 & 30.41 & 8.79 \\
\hline $\mathrm{I}_{\mathrm{SILO}}$ vs $\mathrm{I}_{\mathrm{GC}}(4741)$ & -0.11 & -2.17 & -1.59 & 0.19 & -0.01 & 0.19 & -0.69 & 0.03 & -0.58 & -0.42 & 9.33 & 6.46 \\
\hline \multicolumn{13}{|c|}{ RMSE } \\
\hline SILO vs NSG (370) & 2.70 & 12.19 & 2.62 & 10.02 & 12.03 & 1.28 & 1.28 & 0.16 & 1.67 & 1.28 & 679.85 & 256.89 \\
\hline $\mathrm{I}_{\text {SILO }}$ vs $\mathrm{I}_{\mathrm{NSG}}(4741)$ & 2.71 & 10.67 & 2.96 & 5.42 & 5.82 & 1.16 & 2.08 & 0.21 & 2.18 & 1.63 & 363.23 & 141.70 \\
\hline $\mathrm{I}_{\mathrm{NSG}}$ vs $\mathrm{I}_{\mathrm{GC}}(4741)$ & 3.16 & 13.65 & 3.47 & 6.74 & 6.55 & 1.43 & 2.39 & 0.22 & 2.56 & 1.82 & 443.06 & 168.16 \\
\hline $\mathrm{I}_{\mathrm{SILO}}$ vs $\mathrm{I}_{\mathrm{GC}}(4741)$ & 3.10 & 13.66 & 3.97 & 7.03 & 6.32 & 1.55 & 2.65 & 0.28 & 2.83 & 2.11 & 451.82 & 169.84 \\
\hline \multicolumn{13}{|c|}{ NSE (no units) } \\
\hline SILO vs NSG (370) & 0.90 & 0.89 & 0.93 & 0.90 & 0.88 & 0.90 & 0.96 & 0.93 & 0.95 & 0.93 & 0.91 & 0.91 \\
\hline $\mathrm{I}_{\mathrm{SILO}}$ vs $\mathrm{I}_{\mathrm{NSG}}(4741)$ & 0.84 & 0.85 & 0.90 & 0.90 & 0.89 & 0.86 & 0.88 & 0.89 & 0.89 & 0.85 & 0.90 & 0.91 \\
\hline $\mathrm{I}_{\mathrm{NSG}}$ vs $\mathrm{I}_{\mathrm{GC}}(4741)$ & 0.80 & 0.81 & 0.88 & 0.86 & 0.80 & 0.83 & 0.86 & 0.86 & 0.86 & 0.83 & 0.86 & 0.87 \\
\hline $\mathrm{I}_{\mathrm{SILO}}$ vs $\mathrm{I}_{\mathrm{GC}}(4741)$ & 0.77 & 0.78 & 0.85 & 0.84 & 0.80 & 0.80 & 0.84 & 0.84 & 0.84 & 0.78 & 0.85 & 0.86 \\
\hline
\end{tabular}

${ }^{1}$ NSW Department of Primary Industries, Wagga Wagga Agricultural Institute, NSW 2650, Australia

${ }^{2}$ Climate Change Research Centre, University of New South Wales, Sydney, NSW 2052, Australia

${ }^{3}$ ARC Centre of Excellence for Climate Extreme, University of New South Wales, Sydney, NSW 2052, Australia

${ }^{4}$ New South Wales Office of Environment and Heritage, Department of Planning and Environment, NSW 2620, Australia

${ }^{5}$ NSW Department of Primary Industries, Orange Agricultural Institute, NSW 2800, Australia

This is the author manuscript accepted for publication and has undergone full peer review but has not been through the copyediting, typesetting, pagination and proofreading process, which may lead to differences between this version and the Version of Record. Please cite this article as doi: $10.1002 /$ joc.6371 
${ }^{6}$ NSW Department of Primary Industries, Queanbeyan, NSW 2620, Australia

*Corresponding author: De Li Liu, NSW Department of Primary Industries, Wagga Wagga Agricultural Institute, NSW 2650, Australia

T: +61 0269381933 |F: +61 026938 1809, Email: de.li.liu@dpi.nsw.gov.au

\begin{abstract}
Spatial modelling of agricultural production has been more frequently analysed to assist with regional and long-term planning. Typically, point-scale crop models are used to construct these analyses with researchers using various sources of input data, including observed and interpolated gridded climate data. Understanding the implication of data choice on production estimates is crucial to appreciate the consequences of selecting methodological approaches for agricultural model outputs. In this study, we compared site observed climate data and gridded datasets interpolated from site observations that are commonly used the Australian climate dataset. We assessed the consequences of the differences in climate variables (biases) to the modelled outputs. Our results showed that the major differences between gridded and observed climate datasets were for rainfall variables. Interpolated gridded data tended to have larger rainfall frequency and smaller rainfall intensity, leading to lower surface runoff and higher soil evaporation that caused less plant water uses and less nitrogen uptake, and ultimately resulted in biases in simulated crop biomass and yield. In addition, the results indicated that agricultural models implemented with gridded data could produce similar overall model outputs as those driven by observed climate data, but can result in more uncertainties in simulated spatial outputs. This is particularly evident in regions with high rainfall. Our results showed that applying agricultural models with observed data and then interpolating these results spatially may be the optimal approach to minimise the biases in production modelling outputs and reduce computing time and storage.
\end{abstract}

KEYWORDS: Rainfall, Rainfall intensity, Rainfall Probability, SILO, Interpolation, Gridded Climate, APSIM, Wheat, Bias, Soil Water Balance

1 INTRODUCTION

This article is protected by copyright. All rights reserved. 
The agriculture sector is an integral component for strategic regional planning across wide areas and for long time horizons. Some examples include planning for sustainable regional development, agricultural resource planning, adapting to climate change and securing food and energy supply (Hansen and Jones, 2000). To incorporate agricultural production into strategic plans at broad spatial and temporal scales, agricultural system models are frequently utilised. Agricultural system models have been calibrated and validated using single point field observed experimental data to set biophysical functions and parameters of crop physiology and development (Holzworth et al., 2014). Thus, application of crop models spatially which were designed and calibrated using point scale data, has attracted extensive attention. Indeed, spatial modelling is now a common and useful tool for agricultural system studies (Beaujouan et al., 2001; Faivre et al., 2004; Lv et al., 2018; Priya and Shibasaki, 2001).

Researchers tend to use one of three main methods to create spatial results from point scale crop models. One approach is to run crop models at gridded cells, which requires input data such as climate, soil, crop genotype and farming management for each grid cell. For example, Priya and Shibasaki (2001) used the EPIC model (Williams et al., 1984) executed in $10 \mathrm{~km}$ and $50 \mathrm{~km}$ grid cells to simulate wheat, maize and rice production in India. Similarly, Yu et al. (2014) ran the Agro-C model (Huang et al., 2009) in $10 \mathrm{~km}$ grids across the rice area in China to assess the impact of climate change on rice yield. This approach using gridded climate data to investigate spatial agricultural production can be challenged by a computational perspective, particularly for multiple scenarios and high resolution grids. Consider Lv et al. (2013) as an example, who ran the WheatGrow model (Yan et al., 2000) at 10-km grids to assess the impacts of climate change on regional production of winter wheat in China. The model was run on each of 14,212 grid cells, and evaluated for 3 different future time periods and 3 GCMs projection scenarios. For assessments such as these, many grid cells are likely to share the same input data (e.g., climate, soil and farm management) and it may not be necessary to run every grid cell.

An alternative approach is to run models on representative cells and this is the second frequently used method to scale up single point agricultural systems. Zhang and Yang (2016) used this approach to study rice yield gaps in China. They interpolated climate data from 756 observation stations to $10 \mathrm{~km}$ grid cells and then extracted climate information from the gridded data for 1561 counties. Zhao et al. (2013) used representative cells to assess the impact of agricultural management practices on soil organic carbon in Australian wheat systems. They classified the potential Australian cropping area into 38 climate clusters overlaid with 13 soil types to create 9432 climate-soil units. Climate data for each unit were extracted from Australian $5 \mathrm{~km}$ gridded data. Using 125 management scenarios, they ran 1.18 million simulations of 
APSIM (Agricultural Production Systems sIMulator) (Holzworth et al., 2014), instead of running several million simulations at the $5 \mathrm{~km}$ gridded climate dataset minimising computing time.

The third approach commonly used is to run agricultural production models at sites where observed climate data are available, then interpolate the model outputs to the spatial scale. Using this methodology, Liu et al. (2014b) assessed the value of incorporating wheat residue to sequester soil carbon in the New South Wales wheat belt by running APSIM at 509 observed climate stations in conjunction with 169 soil data sets from APSoil database (https://www.apsim.info/Products/APSoil. aspx). They then used the climate change adaptation strategy tool (CCAST) (Liu et al., 2011) for spatial interpolation. In a similar study Wang et al. (2017) ran the APSIM model at 814 climate sites with 121 observed soil sites to study the impacts of climate change on wheat phenology, yield and water use efficiency, and also used CCAST to interpolate the site output data to a wider spatial scale. A recent study of Wang et al. (2019) illustrates the potential computing efficiency of this methodology. They executed 1,038,960 APSIM simulations (i.e., 346,320 by 3 crops) at 370 sites under 24 farm management options to assess climate change impacts on the three major cropping systems. The same set of runs at $5 \mathrm{~km}$ gridded cells would have required over 13 million simulations.

Collectively these studies use different approaches for spatial modelling, so it is necessary to assess the impacts of the uncertainties in different input data on outputs of crop modelling and it is crucial importance of using appropriate input data for reliable crop modelling outputs. Many studies were conducted that have examined the effect of grid size of input data on agro-ecosystem modelling results. Grosz et al. (2017) showed that the aggregation of soil data strongly affected modelled soil carbon (SOC) trends. Biases associated with simulated SOC changes deceased with increasing spatial resolution. Zhao et al. (2015a) found that a decrease in resolution of gridded climate data led to a decrease in the spatial variability of simulation results but an increase in spatial biases. They concluded that high resolution input data is required to capture the spatial variability in heterogeneous regions. Hoffmann et al. (2015) evaluated the effect of grid resolution of input data on 13 crop models for winter wheat and silage maize and found that radiation for wheat and temperature for maize were the most important climate variables in determining the model-specific input data aggregation on simulated yields. They concluded that large-scale simulations using higher temporal and/or spatial resolution could be systematically biased.

Other studies revealed the sensitivity of agricultural production models to the resolution of input data is associated with particular input variables. Kersebaum and Wenkel (1998) showed that aggregation of climate data and land use data had much more effect on model results than aggregation of soil data. 
Angulo et al. (2014) found that four crop model simulations with three different resolutions of soil data produced only small differences in outputs for wheat cropping systems. This was due to the high rainfall in the region which masked differences in soil water holding capacity.

Certainly quality input data is crucial for robust modelling. Van Wart et al. (2013) found that robust estimation of regional crop yields required specific information on crop management, accurate long term daily climate data and a wide representation of the study area. These authors specifically recommended the use of observed weather data at daily time steps rather than monthly or derived data. This assertion is supported by the widely accepted finding that aggregation of climate data can result in modelling output biases, particularly in regions with complex topography (Zhao et al., 2015b). Given the preference for observed data in modelling processes and the complexity associated with interpolation it is surprising that there have been only a few studies that compare observed climate data with those from gridded climate data. In Australia, Beesley et al. (2009) did compare the 5 km BAWAP (Australian Water Availability Project) (Jones et al., 2009) and 5 km SILO gridded rainfall datasets (Jeffrey et al., 2001) with observed rainfall station data. They found that both datasets contained a small positive bias in dry day rainfall and a negative bias in wet day rainfall, but both overestimated the number of wet days, particularly the BAWAP dataset. Tozer et al. (2012) showed that both Australian gridded datasets they assessed were significantly different to gauged rainfall data and did not often capture gauged extreme events.

Although a few evaluations of the quality of gridded climate data have been assessed against observations (Beesley et al., 2009; Essou et al., 2016), a similar assessment for modelled agricultural production is needed. This assessment will provide knowledge on the implication of different input data on estimates of agricultural production, which is particularly pertinent for studies evaluating climate change impacts. Accordingly, the aims of this study are to 1) analyse differences between gridded and observed climate data, 2) compare simulated APSIM outputs forced with gridded data and forced with observed climate data for a major wheat-growing area in eastern Australia, 3) compare spatial modelling results between interpolated climate and simulated outputs for selected sites and coincident gridded cells and 4) quantify the contribution of the biases in climate gridded variables to the biases in agricultural modelling outputs.

\section{MATERIALS AND METHDODS}

\subsection{Study domain}


To assess the impact of different climate input data on agricultural crop model outputs we selected an important agricultural area, the Murray-Riverina cropping region (MRC), for the study domain. The MRC is located in southern New South Wales and covers an area of 125,551 $\mathrm{km}^{2}$ (Liu et al., 2019). The region is characterised by a semi-arid climate with a long term annual rainfall of $495 \mathrm{~mm}$ and long term average temperature of $9.3^{\circ} \mathrm{C}$ (daily minimum temperature) and $22.0^{\circ} \mathrm{C}$ (daily maximum temperature).

\subsection{Climate data}

Observational data for this study were downloaded from the SILO (Scientific Information for Land Owners) patched point database (PPD) (Jeffrey et al., 2001). This database is an enhanced climate database which has been structured using observational data with missing data estimated using spatial algorithms (Jeffrey et al., 2001). The observational climate data are maintained by the Australian Bureau of Meteorology with a network of rainfall and climate recording stations (Jeffrey et al., 2001). The datasets are freely available at https://legacy.longpaddock.qld.gov.au/silo/. SILO PPD data have been extensively used for running point-scale models in Australia (Ranatunga et al., 2008).

In selecting the gridded dataset for analyses, the two currently available Australian-wide gridded climate datasets were considered, BAWAP and SILO gridded datasets. Previous comparisons between the two gridded datasets (Beesley et al., 2009; Tozer et al., 2012) suggest that the SILO gridded dataset is better fitted to observational rainfall data, which is a key variable in agricultural modelling. Further, the SILO gridded dataset has been used extensively in many Australian studies (Chiew et al., 2008; Tozer et al., 2012). As a result, we used the SILO gridded dataset in this study. The overall method for interpolation of the SILO gridded dataset was a thin plate smoothing spline (Hutchinson, 1995; Hutchinson, 1998) which was used for interpolation of all climate variables. Rainfall was subjected to additional data treatments, which included removal of site stations with large residuals under cross validation and disaggregating the normalised monthly values to daily values using the relative temporal distribution generated by ordinary Kriging of the observed daily values within each month (Jeffery, 2006; Jeffrey et al., 2001). The SILO gridded dataset has been computed on a regular $0.05^{\circ}$ grid over Australia. There are 370 SILO (Scientific Information for Land Owners) PPD (patched point database) observed sites and 4741 SILO gridded cells of $5 \mathrm{~km}\left(0.05^{\circ}\right.$ by $\left.0.05^{\circ}\right)$ in this region (Fig. 1).

\subsection{APSIM model and biophysical modelling}

APSIM is a biophysical model that has been extensively applied to agronomic (Ludwig and Asseng, 2010) and climate change impact and adaptation studies (Wang et al., 2015; Yang et al., 2014). APSIM version 7.7 (Holzworth et al., 2014) was used to estimate wheat yields in the study area. Outputs 
from APSIM using observed and gridded input climate data were compared. The key APSIM modules used in this study were the crop (Wheat), soil water balance (SoilWat), soil nitrogen (SoilN), surface organic matter (SurceOM) and crop management action (Manager). Detailed description of these modules is available in Holzworth et al. (2014). For an emphasis on study of soil water balance in this study, a brief outlining on soil module is given here. SoilWat is largely based on CERES (Jones and Kiniry, 1986) and PREFCT (Littleboy et al., 1992) with a number of enhancements. The main soil properties for specifying soil water characterises are low limit (LL15), field capacity (DUL) and saturation (SAT) in units of volumetric water content $\left(\mathrm{mm}^{3} \mathrm{~mm}^{-3}\right.$ or $\left.\mathrm{mm} \mathrm{mm}^{-1}\right)$. Soil water movement between layers is described by saturated or unsaturated flow that can simultaneously move solutes such as nitrate-N and urea-N. Soil water evaporation is assumed to occur at a constant amount for sufficiently wet soil or by a falling rate after soil water decreasing to a certain level. Importantly, one of the APSIM's improvements in the CERES approach is that small rainfall events are now lost during the initial stage of soil evaporation rather than by the slower process of second stage evaporation.

In our crop modelling simulations, we used the nearest soil types to the climate sites with a total of 56 soil types identified from APSoil (https://www.info/Products/APSoil.aspx). The majority of soil textures in this region were sandy clay and sandy loam above a clay layer and these soil types ranged from Sodosols to Kandosols (Isbell, 2016).

We ran the APSIM model forced by each of the 370 observed climate sites (SILO), the gridded cells which were located with those 370 observed sites (NSG) and the $44715 \mathrm{~km}$ gridded climate cells (GC) using the same settings of APSIM. To assess the responses of the wheat cropping system to different sources of input climate data, we ran APSIM at $\mathrm{N}$-application of $85 \mathrm{~kg} \mathrm{ha}^{-1}$, and 50\% residue incorporation using a single tillage pass, resulting in simulations using a common farming practice applied in the study region.

The sowing date (SD) of wheat crop was as described in Liu et al. (2019) which considers soil water content, recent rainfall, day of year at the time of sowing as well as the soil water-holding characteristic (i.e., plant available water capacity, PAWC) to suit the large spatial conditions. This is an innovative sowing rule compared with the traditionally applied sowing rule based on only simple recent cumulative rainfall (Wang et al., 2017; Wang et al., 2011). Within the sowing window (April 21 to June 30), a winter-type wheat variety "Braewood" was sown before May 24 or a spring-type variety "Ventura" was sown on or after May 24. If the sowing rule was not met on June 30, the crop must be sown on this day to ensure a crop sown every year. 
Because the study compared wheat crop responses to the different input climate datasets for the period 1958-2017, APSIM was reset on 1 February of each year to the initial soil conditions at a moderately low value for soil water and nitrogen quantities. This avoided complexities associated with the cumulative effects of soil water and nitrogen and the interaction of carry-over effects from the previous season.

\subsection{Statistical analyses}

We compared the SILO (370 sites) and NSG (370 grid cells) based on daily (21915 days), monthly (720 months), yearly and growing seasons (60 years) values for the period 1958-2017. We applied pairedtests to examine whether observed climate variables and the corresponding gridded variables were significantly different. The same test was also applied to key outputs of APSIM simulations forced by observations, NSG and the 5-km grid data (GC).

In this study, we defined bias in the gridded dataset as the difference between the values in the gridded cells $\left(X_{g}\right)$ and their respectively observed values $\left(X_{o}\right)$. Similarly, we defined the consequent modelled biases as the difference between the APSIM-simulated outputs forced by gridded data $\left(X_{g}\right)$ and those forced by observations $\left(X_{o}\right)$. We therefore defined mean bias error (MBE) as the difference in the mean over the assessed period between observed and gridded climate data for the mean values of APSIM simulated outputs forced with different climate data (Liu et al., 2019).

To compare the spatial modelling interpolation between the site and gridded data, we also interpolated the two sources of data (i.e., 370 SILO data, 370 NSG) using the inverse distance weight (IDW) method by Climate Change Adaptation Tool (CCAST) (Liu et al., 2009) at 5-km resolution, resulting in the same number of grid cells (4741) as the GC data. We compared the site-specific climate variables and the APSIM outputs forced by these climate data between the 370 SILO and NSG using mean absolute error (MAE), root mean squared error (RMSE) and modified Nash-Sutcliffe efficiency (NSE). The same tests were applied to these data for the respective 4741 interpolated gridded values from the 370 SILO and NSG, together the 4741 GC gridded values, i.e., three pairs from the three interpolated data (4741 $\mathrm{I}_{\mathrm{SILO}} \mathrm{I}_{\mathrm{NSG}}$ and $\mathrm{I}_{\mathrm{GC}}$ data). The tests assessed the differences between the climate variables and the differences in the APSIM outputs forced with the different climate datasets. MAE and RMSE measured the magnitude of errors and NSE assessed the goodness of fit of the interpolated data to the observed data. The original NSE is a normalised index ( $\infty$ to 1.0) that compares the mean square error generated by the modelled simulation to the variance of the target output sequence (Nash and Sutcliffe, 1970). An NSE value $=1.0$ means perfect modelled values (interpolated) matching targeted values (observed values); NSE 
value $=0$ indicates the modelled output equally as good as the use of the mean values of the observed data (Schaefli and Gupta, 2007). Further, an NSE value < 0 suggests the modelled values are questionable as the model prediction skill is lower than observed mean values. However, Krause et al. (2005) recognised that the original NSE is sensitive to large values and insensitive to small values due to the squared parameters and subsequently proposed the use of the sum of the absolute difference between the modelled and observed values instead of the sum of the squared differences. Therefore, we used the modified NSE in this study. The three statistics are calculated as

$$
\begin{aligned}
& M A E=\frac{\sum_{i=1}^{n}\left(X_{g, i}-X_{o, i}\right)}{n} \\
& R M S E=\sqrt{\frac{\sum_{i=1}^{n}\left(X_{g, i}-X_{o, i}\right)^{2}}{n}} \\
& N S E=1-\frac{\sum_{i=1}^{n}\left|X_{o, i}-X_{g, i}\right|}{\sum_{i=1}^{n}\left|X_{o, i}-\overline{X_{o}}\right|}
\end{aligned}
$$

where $n$ is the number of entrances ( 370 sites or 4741 grids).

The climate variables assessed were solar radiation (SR), maximum temperature (TX), minimum temperature (TI), rainfall (Rn), rainfall intensity (RI), and rainfall probability (RP). The key APSIM wheat variables assessed were run off (RO), deep drainage (DD), soil evaporation (CES), water uses by plant (WU), nitrogen uses by plant (NU), sowing date (SD), sowing to flowering (STF), flowering to harvesting (FTH), crop duration (CD), harvesting date (HD), biomass (BM) and crop yield (CY).

The contributions of climate variable biases to the biases in APSIM outputs were quantified by a multiple-linear regression analysis of

$$
M B E_{X}=a M B E_{S R}+b M B E_{T X}+c M B E_{T I}+d M B E_{R n}+e M B E_{R I}+f M B E_{R P}
$$

where the subscription X represents the APSIM simulated variables.

Prior to conducting the regression analysis, we detected whether there was any statistical evidence of collinearity among climate $\mathrm{MBEs}$ (i.e., $\mathrm{MBE}_{\mathrm{SR}}, \mathrm{MBE}_{\mathrm{TX}}, \mathrm{MBE}_{\mathrm{TI}}, \mathrm{MBE}_{\mathrm{Rn}}, \mathrm{MBE}_{\mathrm{RI}}$ and $\mathrm{MBE}_{\mathrm{RP}}$ for $\mathrm{MBE}$ in SR, TX, TI, Rn, RI and RP, respectively) by calculating the variance inflation factor (VIF) (Doetterl et al., 2015). VIF $F_{i}$ for the $i$ th variable was defined as $V I F_{i}=1 /\left(1-R_{i}^{2}\right)$ (Stine, 1995), hence VIF $F_{\mathrm{i}}$ varies from 1 to 
$+\infty$. The $R_{i}^{2}$ is the coefficient of determination from the regression of the $i$ th variable on the other variables. The threshold of $V I F_{i} \geq 10$ was used to infer statistical evidence of significant collinearity (Doetterl et al., 2015): if the $i$ th variable can be accounted by at least $90 \%$ variance $\left(R_{i}^{2} \geq 0.9\right.$, namely $V I F_{i} \geq 10$ ) by using other variables, this variable has statistically significant collinearity with other variables, hence it should not be necessarily included in the regression analysis.

\section{RESULTS}

\subsection{Validation of climate data}

\subsubsection{Comparison of observations with the gridded data}

Table 1 shows the proportion of SILO sites that had significant differences $(\mathrm{P}<0.05)$ between the observed and gridded values at four temporal scales, i.e., daily, monthly, yearly and crop growing season. The paired-test for radiation showed that daily (11.4\%), monthly (3.5\%), yearly (2.2\%) and growing season $(13.2 \%)$ were significantly different $(\mathrm{P}<0.05)$ from the SILO observed data (Table 1$)$. In contrast, the test for rainfall showed statistical differences $(\mathrm{P}<0.05)$ between 47 and $59.5 \%$ of sites across the four temporal scales (Table 1). In general, daily, monthly and yearly data showed a decrease in the proportion of SILO sites significantly different due to the aggregated effects of the temporal scales. It is worth noting that a large proportion of radiation in both SILO PPD and SILO gridded data were calculated rather than actually observed, which may explain the relatively smaller differences between gridded data and observed values. The significant differences in rainfall and rain characteristics compared to temperature are largely due to the stochastic nature of rainfall events which are difficult to model spatially (Jeffrey et al., 2001).

\subsubsection{Relationships between MBEs in rainfall, rain intensity and rain probability}

In the semi-arid environment of the study area, rainfall characteristics such as frequency of rainfall events (i.e., RP) and rainfall intensity (i.e., RI) are important because they influence crop growth and productivity by altering soil moisture, water balance and moisture availability. For RP and RI, approximately three quarters of stations (73.5 to $78.4 \%$ ) were significantly different between the gridded and the observed data at monthly, yearly and growing season time periods. Given the importance of rainfall for production and the large proportion of significant rainfall paired tests for gridded-observed data comparison, we considered it worthwhile to conduct additional analysis to examine the relationship between rainfall characteristics. 
The most distinct relationship depicted in Figure 2 was that RI mean bias error (MBE) was consistently negatively correlated with RP MBE, irrespective of whether the gridded annual rainfall was larger (green colour) or smaller (red colour) than observed values. The sign (+ or -) of intercepts was largely the same sign of rainfall MBE. The MBE for gridded rainfall had almost all higher RP and lower RI (Fig. 2), laying the most MBE points (sites) in the quadrant II. Furthermore, the regression of the data combining all sites showed the relationship of RI MBE was near perfectly described $\left(\mathrm{R}^{2}=0.95-0.97\right)$ with a slope of $-0.76 \sim-0.94$ for RP MBE and a slope of 0.72 0.94 for rainfall MBE at the monthly scale. This suggests that interpolated rainfall produced more frequent but less intense rainfall events than the observed rainfall events.

Further assessment of the consequences of differences in MBE between observed and gridded climate was based on outputs from crop modelling for the growing season. Figure 3 shows the spatial distribution of significantly different gridded-observed compared sites for the wheat-growing season using modelled sowing-to-harvesting dates. Here, the eastern higher rainfall areas of the study region tended have a greater proportion of sites with significantly different MBEs. The averaged MBEs of the significant grid-observed pairs were small for radiation $(-0.1 \pm 1.3 \%)$, maximum temperature $\left(0.0 \pm 0.3{ }^{\circ} \mathrm{C}\right)$, minimum temperature (0.0 \pm 0.2$)$ and rainfall $(1.2 \pm 3.8 \%)$, whilst MBE values were quite large for RI (-14.6.1 $\pm 9.2 \%)$ and RP (17.1 $\pm 11.3 \%)$. The high $10 \%$ tail ( $\geq 90^{\text {th }}$ percentile) of RP was $32.1 \%$, while the low $10 \%$ tail ( $\leq 10^{\text {th }}$ percentile) of RI was $-26.7 \%$, suggesting that interpolated grid cells had $10 \%$ of significant stations with over $25 \%$ both reduction in RI and increase in RP.

For variables considered over the growing season, the overall average MAE value between the observations and NSG was 0.00 for SR, TX and TI, and -2.56 mm for rainfall, $0.63 \mathrm{~mm} \mathrm{rn}^{-1}$ for RI and $3.46 \%$ for RP (Table 2). RMSE across the 370 sites showed small overall differences between the observations and NSG for SR $\left(0.08 \mathrm{MJ} \mathrm{m}^{-2}\right)$, TX $\left(0.12^{\circ} \mathrm{C}\right)$ and $\mathrm{TI}\left(0.09{ }^{\circ} \mathrm{C}\right)$. Differences in RN, RI and RP were $15 \mathrm{~mm}, 0.9 \mathrm{~mm} \mathrm{rn}^{-1}$ and $4.7 \%$, respectively. NSEs of 0.4 for RI and RP further indicate that the gridded rainfall could result in poorly modelled rainfall intensity and rainfall probability when compared with observed rainfall characteristics.

\subsubsection{Spatial comparison between IDW interpolated site climate variables and selected gridded data with the $5 \mathrm{~km}$ gridded data}

Figure 4 shows the spatial maps for six climate variables interpolated from 370 station data (SILO), and from the 370 gridded cells (NSG), compared with data for 4471 grid cells (GC) within the study area. The spatial differences between each two maps ( $\mathrm{I}_{\mathrm{NSG}}-\mathrm{I}_{\mathrm{SILO}}, \mathrm{I}_{\mathrm{GC}}-\mathrm{I}_{\mathrm{SILO}}, \mathrm{I}_{\mathrm{GC}}-\mathrm{I}_{\mathrm{NSG}}$ ) are also 
displayed. Regardless of the data sources (i.e., 370 observations, 370 corresponding grid cells or all grid cells) used, the resultant average values of the 4741 grids had very small differences in MAE for SR (0.00 MJ m$\left.{ }^{-2}\right)$, Tx $\left(0.00-0.04{ }^{\circ} \mathrm{C}\right)$ and TI $\left(0.00-0.03{ }^{\circ} \mathrm{C}\right)$, and RMSE for SR $\left(\leq 0.04 \mathrm{MJ} \mathrm{m}^{-2}\right)$, TX $\left(\leq 0.36{ }^{\circ} \mathrm{C}\right)$ and $\mathrm{TI}\left(\leq 0.24^{\circ} \mathrm{C}\right)$. The three data-source maps show nearly identical spatial patterns for maximum, minimum and radiation across the region, apart from the $1.5{ }^{\circ} \mathrm{C}$ and $1.1{ }^{\circ} \mathrm{C}$ differences in $1 \%$ cells of TX and TI (Figs. 4A \& B). This suggests that apart from more data points used for the spatial interpolation, the overall values for regional maps had small differences, but where there were differences these were large.

In contrast, the overall differences between these maps for RI and RP ranged from -7.8 \pm 6.2 to $20.3 \pm 9.4 \%$ and $7.8 \pm 5.6$ to $21.8 \pm 12.3 \%$, respectively (Fig. 4). NSEs between INSG and ISILO were small, only 0.03 for RI and 0.24 for RP (Table 2). The further tests of statistics defined in Equations 1, 2 \& 3 confirmed the disagreement between the gridded and observed rainfall characteristics (Table 2). The worst case was for the differences between the maps based on 370 stations and 4741 grids, which gave NSE of 0.43 for RI and -0.30 for RP, suggesting that the gridded RI and RP were not consistent with those based on observed data (Table 2).

The overall differences in rainfall between any two maps of $\mathrm{I}_{\mathrm{NSG}} \mathrm{Vs} \mathrm{I}_{\mathrm{SILO}}(0.2 \pm 1.5 \mathrm{~mm}), \mathrm{I}_{\mathrm{GC}}$ Vs $\mathrm{I}_{\mathrm{SILO}}$ $(0.0 \pm 3.9 \mathrm{~mm})$ and $\mathrm{I}_{\mathrm{GC}}$ vs $\mathrm{I}_{\mathrm{NSG}}(-0.1 \pm 3.8 \mathrm{~mm})$ were also small. However, the outliers $(<1 \mathrm{st}$ percentile or $>99$ th percentile) were larger than $16 \mathrm{~mm}$, indicating that, in extreme cases, interpolation can result in differences between observed and gridded values due to the differences from the gridded values. This suggests that differences in some areas could be still large although region-averaged rainfall derived from grid cells and stations was similar (Fig. 4D). Furthermore, this means that it could be misleading to use gridded data as a surrogate for observed data for a specific part of a region.

The key rainfall characteristics (RI and RP) exhibited much larger differences between gridded and observed values (Fig 4E) than the amount of rainfall (Fig 4D). The overall differences of RI maps were $13.6 \pm 7.1 \%\left(\mathrm{I}_{\mathrm{NSG}}-\mathrm{I}_{\mathrm{SILO}}\right),-20.6 \pm 9.4 \%\left(\mathrm{I}_{\mathrm{GC}}-\mathrm{I}_{\mathrm{SILO}}\right)$, and $-7.8 \pm 6.2 \%\left(\mathrm{I}_{\mathrm{GC}}-\mathrm{I}_{\mathrm{NSG}}\right)$. The median differences over the 4741 grids was $-13.6 \%$ ( $\mathrm{I}_{\mathrm{NSG}}$ - $\mathrm{I}_{\mathrm{SILO}}$ ), suggesting that spatial coverage based on grids could have more than half the area recording at least $13 \%$ lower rainfall intensity than observed values. Similarly, the overall differences of RP maps were in the same order of $+12.9 \pm 8.6$ ( $\mathrm{I}_{\mathrm{NSG}}-\mathrm{I}_{\mathrm{SILO}}$ ), $+21.9 \pm 12.3$ ( $\mathrm{I}_{\mathrm{GC}}-\mathrm{I}_{\mathrm{SILO}}$ ), and $+7.8 \pm 5.6 \%\left(\mathrm{I}_{\mathrm{GC}}-\mathrm{I}_{\mathrm{NSG}}\right)$. The median differences over the 4741 grids were $+11.9 \%\left(\mathrm{I}_{\mathrm{NSG}}-\mathrm{I}_{\mathrm{SILO}}\right)$, indicating more than half of the cells were yielding around $12 \%$ greater rainfall probability than observed values (Figs. 4E \& F). These results revealed that interpolated rainfall could produce a similar amount of 
rainfall, but a large distortion in rainfall characteristics, lower rainfall intensity associated with higher rainfall probability.

\subsection{Consequences of using different climate data in biophysical models}

\subsubsection{Comparison of APSIM outputs forced by observations and gridded data}

Only 6-11\% of sites had significantly different $(\mathrm{P}<0.05)$ wheat phenological parameters in APSIM simulations when forced by gridded climate and observed climate data (Fig. 5). This was due to the relatively small differences between gridded and observed temperatures, which is the key climate variable that drives wheat phenology in APSIM. A larger proportion of sites had significantly different values in water-related parameters, consistent with the differences in rainfall characteristics previously explored. Specifically, there were $46 \%$ sites with significant differences in CES values. Consequently, the simulated WU and NU showed $36 \%$ and $47 \%$ of sites had significant differences between the gridded and observed climate yearly values (Fig 5). Impacts of altered rainfall characteristics caused by gridded climate on soil water balance were also notable with $42 \%$ and $23 \%$ of sites recording significantly different RO and DD, respectively. More importantly, a notable proportion of the sites had significantly different crop biomass (38\%) and yield (33\%). These differences in simulated crop growth can produce additional uncertainties for biophysical modelling, if the gridded climate is used as a surrogate for the observed climate.

There were distinct spatial patterns of sites which had significantly different APSIM outputs (Fig. 6). Nearly all the sites with significantly different CES had positive MBEs due to the soil surface being wetter than observed values resulting from smaller and more frequent rain events. As a consequence, soil water and nutrient variables (runoff, plant water and $\mathrm{N}$ use) and crop growth variables (biomass and yield) were smaller (negative MBE) for the simulations forced by the gridded climate than those forced by observed climate data.

\subsubsection{Spatial comparison between the APSIM simulations forced by different sources of climate data}

Spatial maps for the 12 key APSIM outputs were constructed for the three source data (i.e., 370 stations (SILO), 370 grids (NSG) and 4741 5-km grids) (Figs. 7 \& 8). For soil water and phenological variables, overall differences in average values between any two datasets were very small, ranging from $0.0 \pm 0.5$ days (Fig. 8Cd: NSG-SILO) to $2.2 \pm 13.5 \mathrm{~mm}$ (Fig. 7Be: GC-SILO), which was expected as the averaged differences in climate variables were small between the spatial maps generated from the observed climate gridded variables (Fig 4). However, there was an uneven spatial distribution of the differences in the water related APSIM outputs (i.e., RO, DD, CES, WU and NU). This may be expected given the 
uneven spatial distribution of rainfall MBEs (Fig. 4E). The results of larger rainfall MBE in the eastern high rainfall area of the study region corresponded to higher MBE than those for water-related APSIM outputs. Similarly, the results of overall small MBE in temperature (Fig. 3) led to overall small difference in parameters of wheat phenology (Figs 8A-H). These results indicate that the differences between gridded and observed climate data sources can lead to biases in the biophysical modelling outputs, depending on region and crop variable.

Understanding the differences in final biomass (BM) and crop yield (CY) were more complicated than soil water and phenology variables, because modelled crop growth integrates climate variables with environmental factors. Differences across the region were still relatively small, with a range in biomass of 30 to $21 \mathrm{~kg} \mathrm{ha}^{-1}$ and crop yields of -9 to $2 \mathrm{~kg} \mathrm{ha}^{-1}$ (Figs 8G \& F). The relatively large RMSE (680 kg ha for BM and $257 \mathrm{~kg} \mathrm{ha}^{-1}$ for CY) (Table 3) highlights the biases with large spatial variation across the region. Simulated biomass and yield differences tended to be larger in the eastern high rainfall area than in the western low rainfall area, consistent with the climate differences used to drive the biophysical model. Up to $150 \mathrm{~kg} \mathrm{ha}^{-1}$ wheat yield in $10 \%\left(\leq 10^{\text {th }}\right.$ percentile or $\geq 90^{\text {th }}$ percentile) tailed differences indicate divergence in results if the sub-regional spatial modelling is driven by different sources of climate data. The results further confirm that biophysical models driven by gridded data could produce similar overall model outputs as those driven by site climate data, but can generate more uncertainty in crop yields due to different magnitude of climate bias in different regions.

\subsubsection{Relationship of biases in gridded climate and modelled outputs}

Least squared multiple regression analysis (Tables 4 \& 5) established the relationship between biases in gridded climate and APSIM-simulated variables. Our analysis included the MBEs of all gridded climate variables except radiation MBE because the biases were very small (Fig. 4C). This was likely again due to the large proportion of calculated SILO radiation being the same as gridded radiation values. Analysis of the remaining five variables showed that any one of these MBEs had strong collinearity with other climate MBEs across the 12 key APSIM outputs, because VIF ranged from $13.9 \pm 10.1$ to $33.5 \pm 38.8$ (Table 4), much greater than the threshold of 10 (Doetterl et al., 2015). Stepwise regression identified that $\mathrm{MBE}_{\mathrm{RI}}$ and $\mathrm{MBE}_{\mathrm{RP}}$ caused significant collinearity because exclusion of either $\mathrm{MBE}_{\mathrm{RI}}$ or $\mathrm{MBE}_{\mathrm{RP}}$ resulted in no statistical evidence of significant collinearity in the remaining four MBEs (Table 4). When MBE $E_{\mathrm{RP}}$ was excluded in the regression analysis, VIF ranged from $1.78 \pm 2.91$ to $2.99 \pm 2.57$. Similarly, when $\mathrm{MBE}_{\mathrm{RI}}$ was not included in the regression equation, all associated MBEs showed no evidence of statistically significant collinearity as all mean VIFs were smaller than the threshold of 10 . A few sites showed slightly collinearity 


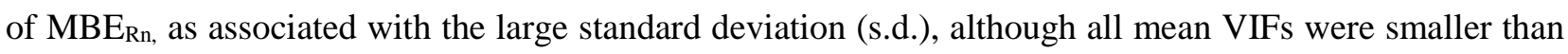
10. Generally, the stepwise analysis showed significant collinearity when $M_{B E}$ and $M B E_{R P}$ were not included at the same time, no matter which climate MBEs were excluded (Table 4, data only shown for CY). This further confirmed that the gridded rainfall resulted in a higher RPs associated with lower RIs.

The contribution of the biases in gridded climate variables to the biases in biophysical modelled outputs was quantified by the regression coefficients in Table 5. The different MBEs of climate variables had different effects on the MBEs in modelled outputs because different functionalities of climate variables were implemented in the biophysical model (Liu et al., 2019). Regression analysis showed that the MBE in climate variables could account for an average of $71-92 \%\left(R^{2}: 0.71 \pm 0.20 \sim 0.92 \pm 0.06\right)$ of the variance in the MBEs for APSIM-simulated phenological parameters. When either MBE $\mathrm{RI}_{\mathrm{RI}}$ or $\mathrm{MBE}_{\mathrm{RP}}$ (for avoiding collinearity) was excluded in the analysis, the phenological MBEs were largely related to the temperature and rainfall MBEs, with significant coefficients for more than one third of sites (Table 5). Temperature biases resulted in negative coefficients for the three crop phenological stages (STF, FTH \& HD). Importantly, the regression analysis revealed a similar response as the impacts of climate change on crop development and growth (Anwar et al., 2015; Liu et al., 2017). For example, an increase of one Celsius degree of TX or TI MBE advanced wheat flowering (STF) by 9.27-9.50 days or 6.03-6.5 days, similar to Anwar et al. (2015) who found future temperatures would shorten wheat flowering by 9-20 days per Celsius degree increase. Similarly, increased wheat yield of $5.62-5.84 \mathrm{~kg} \mathrm{ha}^{-1}$ per mm rainfall MBE was much lower than $20 \mathrm{~kg} \mathrm{ha}^{-1} \mathrm{~mm}^{-1}$ potential yield (French and Schultz, 1984; Sadras and Lawson, 2013). This is because both the positive coefficients for $M B E_{R I}$ and the negative coefficients for $M_{B} E_{R P}$ would reduce the potential rate as RI had a consistently negative MBE and RP a positive MBE. In addition, more than two thirds of sites had significant coefficients in responses of crop growth and soil related parameters. Our results implicate that impacts of the biases in climate variables on biophysical modelled outputs are similar to the crop responses to climate change because models have been built with processing functions able to simulate real crop responses to environmental changes.

\section{$4 \quad$ DISCUSSION}

Use of point-scale agricultural models for spatial modelling has become a common approach for researches to contribute to strategic planning including resource allocation and assessments of climate change impacts in agricultural systems. However, the lack of observed climate and soil data at a fine and consistent scale has led to researchers using a variety of input data sources to produce spatial results from 
these point-scale models. In this study, we compared climate and wheat production outputs between sitebased observations and a commonly used Australian gridded climate dataset (SILO) also between interpolated results from site observed data and gridded values. We assessed the consequences of the climate differences (biases) to the biophysical modelled outputs. We focused on the assessment of climate data impacts on crop models as climate conditions are more important than soil and other factors for crop yield (Kersebaum and Wenkel (1998).

Our results showed that SILO gridded data contained significant biases especially in rainfall which is supported by the findings of Beesley et al. (2009). Additional biases in gridded rainfall contained systemically distorted rainfall characteristics. Specifically, biases in lower rainfall intensity were highly associated with higher rainfall probability. These biases in the gridded climate data were found to flow onto biases in the biophysical modelled outputs (Fig. 5 and Fig. 6). This could result in misrepresentation of production in spatial analyses including climate change impact assessments. This finding is similar to climate biases from other sources such as dynamical downscaling (Liu et al., 2019).

An obvious rationale for using site observed data as inputs to agricultural models is that such models were built to simulate the processes of crop systems at point scale with many specific functions sensitive to the observed climate and weather extreme values. However, the scattered nature of observed data is often considered as inadequate for high resolution spatial modelling, so use of gridded data input has become a preferred choice for researchers (Lv et al., 2013; Lv et al., 2018; Priya and Shibasaki, 2001; Yu et al., 2014). Our study suggests that this approach can cause large errors in the results of spatial modelling. Interpolated gridded rainfall was found to be more frequent and less intense when compared with observations (Fig. 3 \& 4). These changes in frequency and intensity of rainfall will result in less runoff (RO) and more soil evaporation (CES) in the APSIM modelling, leading to negative biases in waterway flows. Thus, this input data could result in biases in hydrological modelled outputs, if they are used to drive hydrological models. The implications of climate biases in agricultural modelling outputs are complicated as many detailed agricultural processes are built into agricultural models. For example, soil nutrients need to dissolve in soil water for plant uptake. Plants will uptake solid elements such as nitrate-N and urea-N passively as a result of water uptake. The negative biases of plant water transpiration resulting from frequent smaller rainfall events would reduce the amount of nutrition uptake by crops and led to nutrient stresses, ultimately resulted in less crop biomass and yield. This means it is important to use quality input data to effectively avoid these consequences in crop modelled outputs (Van Wart et al., 2013). 
As regional climate models (RCMs) have some systematic biases, bias-correction of the RCMs outputs is required (Ji et al., 2016) prior application in climate change impact studies. Gridded climate data are widely used for the bias-correction of RCM's post-processing variables (Evans and Argüeso, 2014). To correct biases in regional climate modelling, regular gridded data such as SILO gridded data that were interpolated from observed sites are usually used. Our study suggests that post-processing bias-correction with the gridded data can result in inherent biases (i.e., more frequent and less intensive rainfall bias from the gridded data treated as observations). This may explain, in part, the large biases that have been found in the bias corrected dynamical downscaling data (Liu et al., 2019). To avoid such additional biases, regional modelling outputs may be interpolated to observational data and bias-correction can be undertaken on station sites using observed station data. This approach has been successfully applied for bias-correction of monthly GCM data in statistical downscaling (Liu and Zuo, 2012; Zhang, 2005).

Agricultural production models require a variety of input data to represent biophysical processes. Climate data is generally considered the most important input data, more so than other inputs such as soil data (Angulo et al., 2014; Kersebaum and Wenkel, 1998; Liu et al., 2014a). Crop models are generally more sensitive to climate than soil information because they were built to represent the crop physiological processes with climate variables, i.e., radiation for converting light energy to biomass accommodation, temperature for crop development, and water for many biochemical medium and growth substances. In contrast, soil has been treated in models as a physical bucket with a size featured as PAWC that receives and stores rain-water and nutrients for plant use. In a year with frequent rainfall events, plants can do equally well regardless of the soil textural characteristics (e.g., a larger or smaller PAWC). However, in a year with longer dry spells, plants grown in a soil with a larger PAWC would produce better yields than with a smaller PAWC soil (Yang et al., 2014). Variations in crop growth caused by soil differences may therefore be indirectly explained by the variation in climate and climate variations, contributing largely to the crop yield inter-annual variations, particularly for a semiarid dry land cropping system such as our study area.

Overall, using gridded climate input data for agricultural crop modelling can lead to large biases in crop yields. These models were built to simulate the processes of crop systems at a point scale and application of such models using gridded climate data may not be valid (Hoffmann et al., 2016). Baron et al. (2005) found that coupling GCM gridded outputs with site-scale crop models could cause large systematic biases due to scale incompatibility. In addition, application of crop models to grid cells significantly increases computing time, data storage and processing. Taking our study as an example, applying crop models on regular grids will take about 13 times (4741 divided by 370) or more computing 
time to execute crops model as using site data. Moreover, interpolating simulated outputs from executing the site model at site scale can result in the same spatial maps, if the gridded data contain few biases (e.g., Fig. 8C, three FTH spatial maps). Therefore, to produce spatial representation of agricultural models we suggest that the application of point-scale crop modelling by using site observed climate and interpolation of the site-modelled outputs to avoid these impediments such as scale incompatibility and additional biases imported from gridded input data.

\section{CONCLUSIONS}

In this study, we assessed differences between observed climate data and the Australian SILO gridded dataset, and quantitatively determined the implications of the climate differences (biases) on climate variables and crop model outputs in an important wheat growing area in eastern Australia. The proportion of the gridded temperatures showing significant differences to the observed temperature was relatively small, but large differences were found for rainfall intensity and rainfall probability. Biases in rainfall characteristics were consistently negative for intensity and positive for frequency. In a large proportion of sites the gridded input data with more frequent and smaller rainfall resulted in APSIMsimulated smaller runoff, less plant water and $\mathrm{N}$ use, and larger soil evaporation and, ultimately, lower biomass and wheat yield. Thus, we concluded that use of gridded climate as a surrogate of site-observed climate could introduce errors to analyses.

Our study also revealed that for the climate variables or simulated outputs with less biases, use of scatter-observed sites or simulated outputs for these sites can produce identical spatial maps to all gridded values. Considering the consistency of site-observed climate with point scale crop models in terms of datamodel compatibility, the potential biases of gridded climate, and the differences in computing time and storage required, we recommend that preference should be given to the use of the site-observed climate and soil information to run crop models at site scales and interpolation of crop modelled outputs for spatial analysis. This research also implies that it is crucially important to assess biases in gridded climate data before using it in bias correction of global climate model projections, analysis of climate extremes or spatial modelling in other disciplines, such as hydrology and ecology.

\section{ACKNOWLEDGMENTS}


This work was supported by the Climate Change Fund as part of the NSW Primary Industries Climate Change Research Strategy. We appreciate Mrs Rebecca Lines-Kelly, former communication officer of Climate Unit, NSW Department of Primary Industries for comments on the manuscript.

\section{References}

Angulo, C. et al., 2014. 'Fingerprints' of four crop models as affected by soil input data aggregation. European journal of agronomy, 61: 35-48.

Anwar, M.R. et al., 2015. Climate change impacts on phenology and yields of five broadacre crops at four climatologically distinct locations in Australia. Agricultural Systems, 132: 133-144.

Baron, C. et al., 2005. From GCM grid cell to agricultural plot: scale issues affecting modelling of climate impact. Philosophical Transactions of the Royal Society of London B: Biological Sciences, 360(1463): 2095-2108.

Beaujouan, V., Durand, P. and Ruiz, L., 2001. Modelling the effect of the spatial distribution of agricultural practices on nitrogen fluxes in rural catchments. Ecological modelling, 137(1): 93-105.

Beesley, C., Frost, A. and Zajaczkowski, J., 2009. A comparison of the BAWAP and SILO spatially interpolated daily rainfall datasets, 18th World IMACS/MODSIM Congress, Cairns, Australia. Citeseer, pp. 13-17.

Chiew, F., Vaze, J. and Hennessy, K.J., 2008. Climate data for hydrologic scenario modelling across the Murray-Darling Basin: A report to the Australian Government from the CSIRO Murray-Darling Basin Sustainable Yields Project. CSIRO Canberra.

Doetterl, S. et al., 2015. Soil carbon storage controlled by interactions between geochemistry and climate. Nature Geoscience, 8(10): 780.

Essou, G.R., Arsenault, R. and Brissette, F.P., 2016. Comparison of climate datasets for lumped hydrological modeling over the continental United States. Journal of hydrology, 537: 334-345.

Faivre, R. et al., 2004. Spatialising crop models. Agronomie, 24(4): 205-217.

French, R. and Schultz, J., 1984. Water use efficiency of wheat in a Mediterranean-type environment. II. Some limitations to efficiency. Crop and Pasture Science, 35(6): 765-775.

Grosz, B. et al., 2017. The implication of input data aggregation on up-scaling soil organic carbon changes. Environmental Modelling \& Software, 96: 361-377.

Hansen, J.W. and Jones, J.W., 2000. Scaling-up crop models for climate variability applications. Agricultural Systems, 65(1): 43-72.

Hoffmann, H. et al., 2016. Impact of spatial soil and climate input data aggregation on regional yield simulations. PloS one, 11(4): e0151782.

Hoffmann, H. et al., 2015. Variability of effects of spatial climate data aggregation on regional yield simulation by crop models. Climate Research, 65: 53-69.

Holzworth, D.P. et al., 2014. APSIM - Evolution towards a new generation of agricultural systems simulation. Environmental Modelling \& Software, 62: 327-350.

Huang, Y. et al., 2009. Agro-C: A biogeophysical model for simulating the carbon budget of agroecosystems. Agricultural and forest meteorology, 149(1): 106-129.

Hutchinson, M.F., 1995. Interpolating mean rainfall using thin plate smoothing splines. International journal of geographical information systems, 9(4): 385-403. 
Hutchinson, M.F., 1998. Interpolation of rainfall data with thin plate smoothing splines. Part I: Two dimensional smoothing of data with short range correlation. Journal of Geographic Information and Decision Analysis, 2(2): 139-151.

Isbell, R., 2016. The Australian soil classification. CSIRO publishing.

Jeffery, S., 2006. Error analysis for the interpolation of monthly rainfall used in the generation of SILO rainfall datasets, Technical report, the Queensland Department of Natural Resources.

Jeffrey, S.J., Carter, J.O., Moodie, K.B. and Beswick, A.R., 2001. Using spatial interpolation to construct a comprehensive archive of Australian climate data. Environmental Modelling \& Software, 16(4): 309-330.

Ji, F. et al., 2016. Evaluation of long-term precipitation and temperature Weather Research and Forecasting simulations for southeast Australia. Climate Research, 67(2): 99-115.

Jones, C. and Kiniry, J., 1986. CERES-Maize: Asimulation model of maize growth and development. Texas A \& M University Press, College Station, Texax.

Jones, D.A., Wang, W. and Fawcett, R., 2009. High-quality spatial climate data-sets for Australia. Australian Meteorological and Oceanographic Journal, 58(4): 233.

Kersebaum, K. and Wenkel, K.-O., 1998. Modelling water and nitrogen dynamics at three different spatial scales-influence of different data aggregation levels on simulation results, Soil and Water Quality at Different Scales. Springer, pp. 313-319.

Krause, P., Boyle, D. and Bäse, F., 2005. Comparison of different efficiency criteria for hydrological model assessment. Advances in geosciences, 5: 89-97.

Littleboy, M. et al., 1992. Impact of soil erosion on production in cropping systems. I. Development and validation of a simulation model. Soil Research, 30(5): 757-774.

Liu, D., Mo, J., Fairweather, H. and Timbal, B., 2009. A GIS tool to evaluate climate change impact: functionality and case study, 18 th World IMACS Congress and MODSIM09 Cairns, Australia: International Congress on Modelling and Simulation, pp. 1936-1942.

Liu, D.L., Anwar, M.R., O'Leary, G. and Conyers, M.K., 2014a. Managing wheat stubble as an effective approach to sequester soil carbon in a semi-arid environment: Spatial modelling. Geoderma, 214: 50-61.

Liu, D.L., Anwar, M.R., O'Leary, G. and Conyers, M.K., 2014b. Managing wheat stubble as an effective approach to sequester soil carbon in a semi-arid environment: Spatial modelling. Geoderma, 214215: 50-61.

Liu, D.L., Timbal, B., Mo, J. and Fairweather, H., 2011. A GIS-based climate change adaptation strategy tool. International Journal of Climate Change Strategies and Management, 3(2): 140-155.

Liu, D.L. et al., 2019. Propagation of climate model biases to biophysical modelling can complicate assessments of climate change impact in agricultural systems. International Journal of Climatology, 39: 424-444.

Liu, D.L. et al., 2017. Crop residue incorporation can mitigate negative climate change impacts on crop yield and improve water use efficiency in a semiarid environment. European Journal of Agronomy, 85: 51-68.

Liu, D.L. and Zuo, H., 2012. Statistical downscaling of daily climate variables for climate change impact assessment over New South Wales, Australia. Climatic change, 115(3-4): 629-666.

Ludwig, F. and Asseng, S., 2010. Potential benefits of early vigor and changes in phenology in wheat to adapt to warmer and drier climates. Agricultural Systems, 103(3): 127-136.

Lv, Z., Liu, X., Cao, W. and Zhu, Y., 2013. Climate change impacts on regional winter wheat production in main wheat production regions of China. Agricultural and forest meteorology, 171: 234-248. 
Lv, Z. et al., 2018. Climate change impacts on regional rice production in China. Climatic Change, 147(3-4): 523-537.

Nash, J.E. and Sutcliffe, J.V., 1970. River flow forecasting through conceptual models part I-A discussion of principles. Journal of hydrology, 10(3): 282-290.

Priya, S. and Shibasaki, R., 2001. National spatial crop yield simulation using GIS-based crop production model. Ecological Modelling, 136(2-3): 113-129.

Ranatunga, K., Nation, E.R. and Barratt, D.G., 2008. Review of soil water models and their applications in Australia. Environmental Modelling \& Software, 23(9): 1182-1206.

Sadras, V.O. and Lawson, C., 2013. Nitrogen and water-use efficiency of Australian wheat varieties released between 1958 and 2007. European Journal of Agronomy, 46: 34-41.

Schaefli, B. and Gupta, H.V., 2007. Do Nash values have value? Hydrological Processes: An International Journal, 21(15): 2075-2080.

Stine, R.A., 1995. Graphical interpretation of variance inflation factors. The American Statistician, 49(1): 53-56.

Tozer, C., Kiem, A. and Verdon-Kidd, D., 2012. On the uncertainties associated with using gridded rainfall data as a proxy for observed. Hydrology and Earth System Sciences, 16(5): 1481-1499.

Van Wart, J., Kersebaum, K.C., Peng, S., Milner, M. and Cassman, K.G., 2013. Estimating crop yield potential at regional to national scales. Field Crops Research, 143: 34-43.

Wang, B. et al., 2017. Spatiotemporal changes in wheat phenology, yield and water use efficiency under the CMIP5 multimodel ensemble projections in eastern Australia. Climate Research, 72(2): 83-99.

Wang, B., Liu, D.L., Asseng, S., Macadam, I. and Yu, Q., 2015. Impact of climate change on wheat flowering time in eastern Australia. Agricultural and Forest Meteorology, 209: 11-21.

Wang, B. et al., 2019. Modelling and evaluating the impacts of climate change on three major crops in south-eastern Australia using regional climate model simulations. Theoretical and applied Climatology, : .

Wang, J., Wang, E. and Liu, D.L., 2011. Modelling the impacts of climate change on wheat yield and field water balance over the Murray-Darling Basin in Australia. Theoretical and Applied Climatology, 104(3-4): 285-300.

Williams, J., Jones, C. and Dyke, P.T., 1984. A modeling approach to determining the relationship between erosion and soil productivity. Transactions of the ASAE, 27(1): 129-0144.

Yan, M., Cao, W., Luo, W. and Jiang, H., 2000. A mechanistic model of phasic and phenological development of wheat. I. Assumption and description of the model. Ying yong sheng tai xue bao= The journal of applied ecology, 11(3): 355-359.

Yang, Y., Liu, D.L., Anwar, M.R., Zuo, H. and Yang, Y., 2014. Impact of future climate change on wheat production in relation to plant-available water capacity in a semiaridenvironment. Theoretical and Applied Climatology, 115(3-4): 391-410.

Yu, Y., Zhang, W. and Huang, Y., 2014. Impact assessment of climate change, carbon dioxide fertilization and constant growing season on rice yields in China. Climatic change, 124(4): 763-775.

Zhang, T. and Yang, X., 2016. Mapping Chinese rice suitability to climate change. Journal of Agricultural Science, 8(6): 33.

Zhang, X.-C., 2005. Spatial downscaling of global climate model output for site-specific assessment of crop production and soil erosion. Agricultural and Forest Meteorology, 135(1): 215-229.

Zhao, G. et al., 2013. Impact of agricultural management practices on soil organic carbon: simulation of Australian wheat systems. Global change biology, 19(5): 1585-1597. 
Zhao, G. et al., 2015a. Effect of weather data aggregation on regional crop simulation for different crops, production conditions, and response variables. Climate Research, 65: 141-157.

Zhao, G. et al., 2015b. Demand for multi-scale weather data for regional crop modeling. Agricultural and Forest Meteorology, 200: 156-171.

This article is protected by copyright. All rights reserved. 


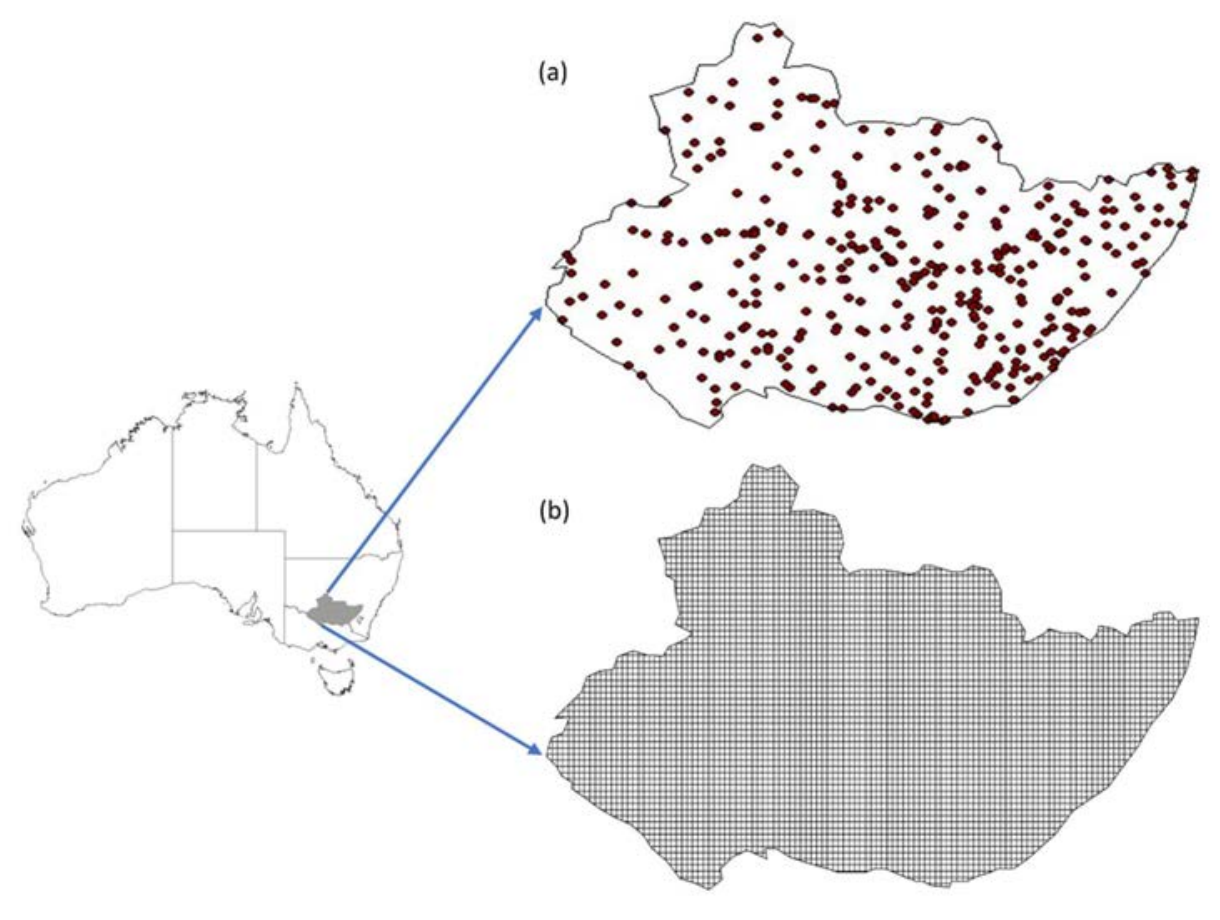

This article is protected by copyright. All rights reserved. 

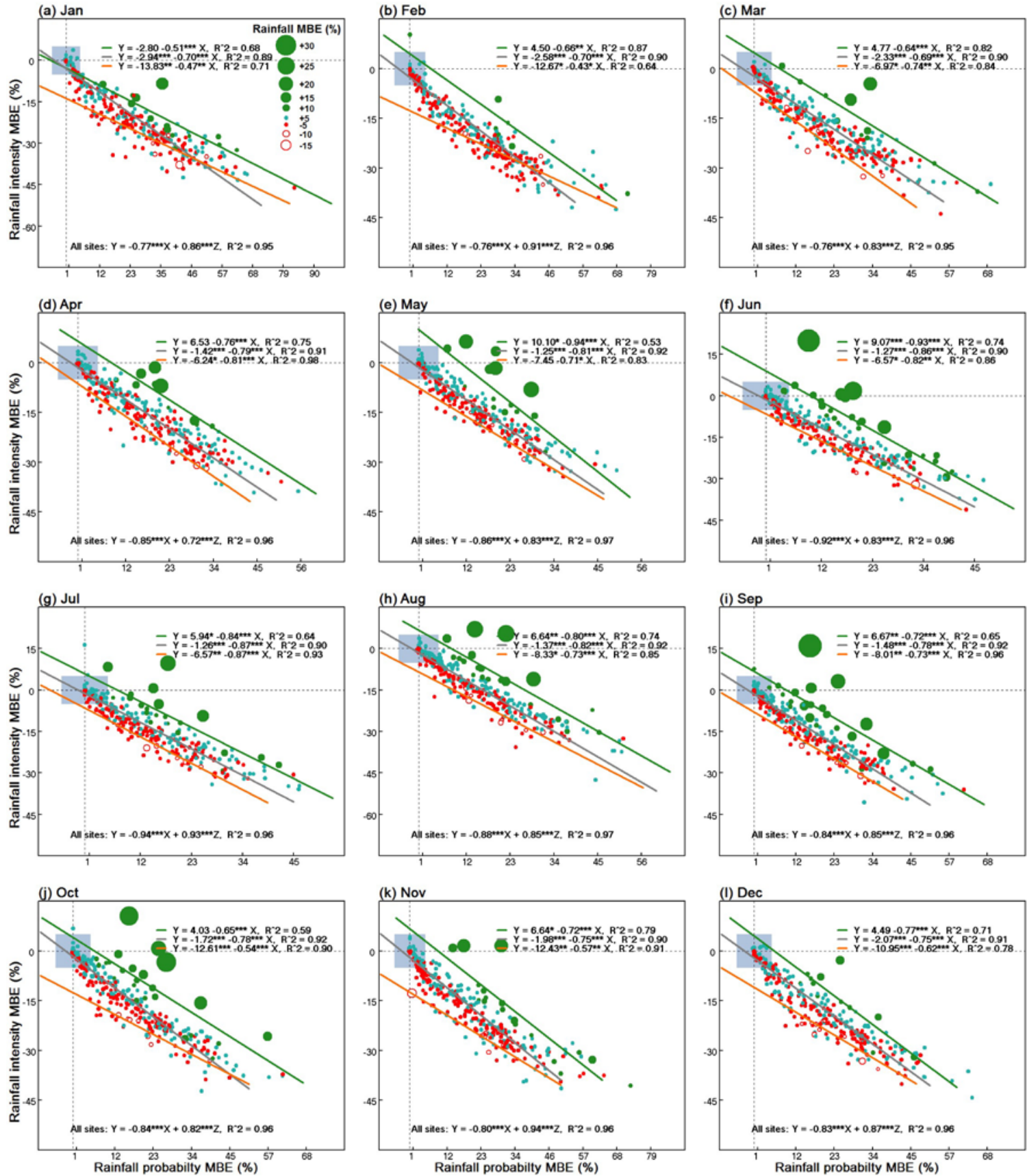
(a) Radiation

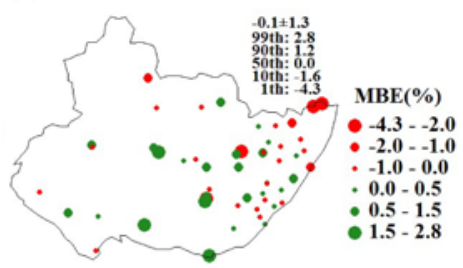

(d) Rainfall

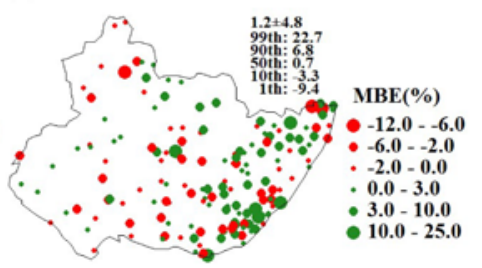

(b) Maximum temperature

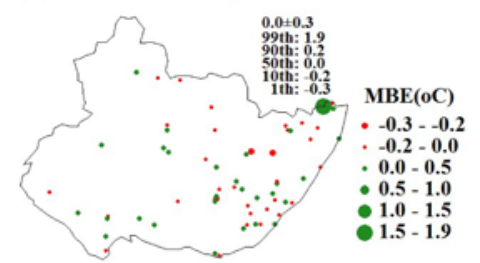

(e) Rain probability

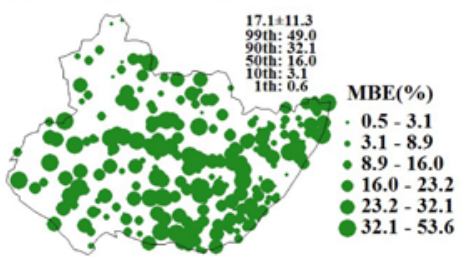

(c) Minimum temperature

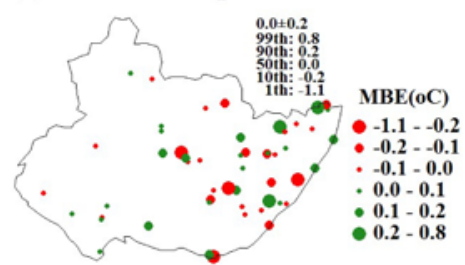

(f) Rain intensity

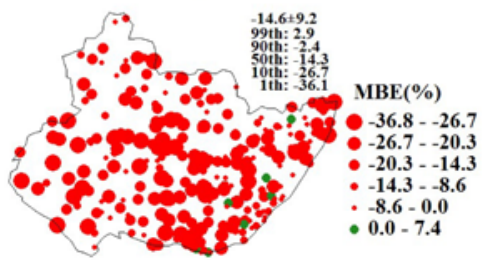




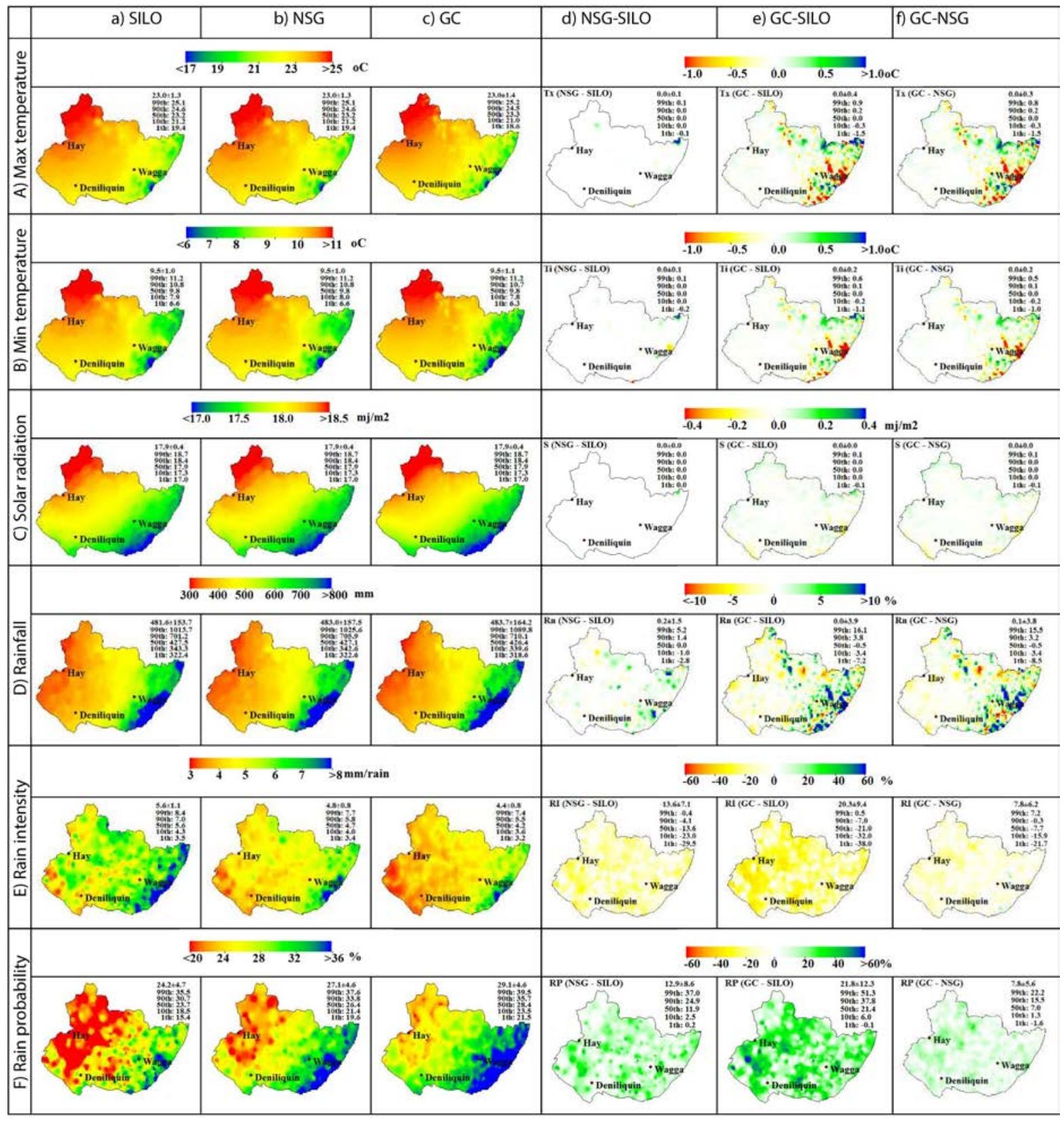




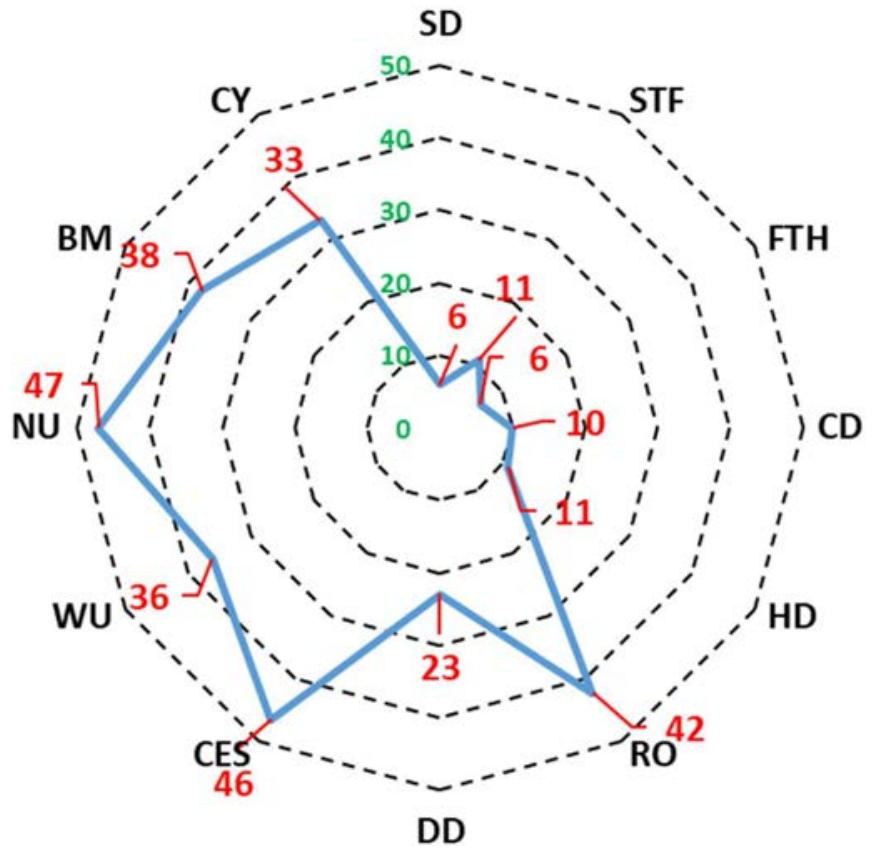




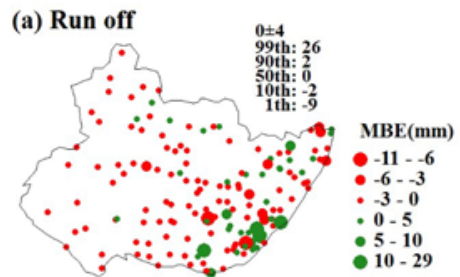

(d) Water use

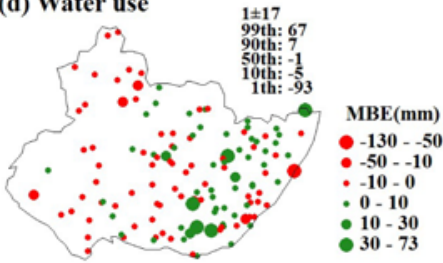

(g) Sowing to flowering

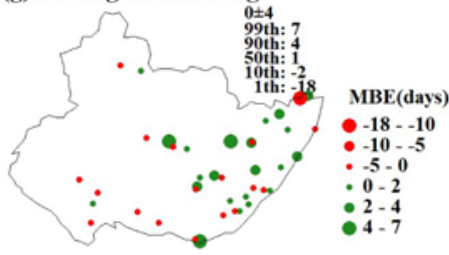

(j) Harvest date

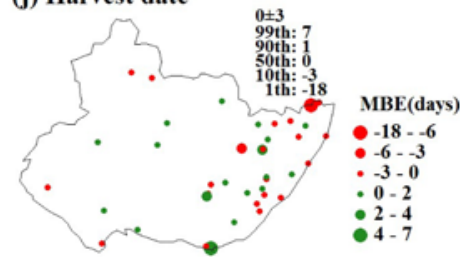

(b) Deep drainage

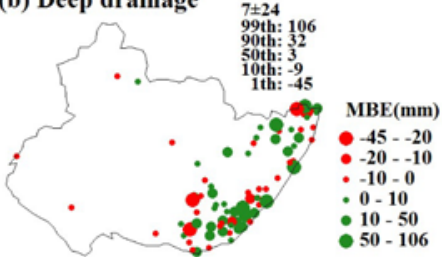

(e) $\mathrm{N}$ use

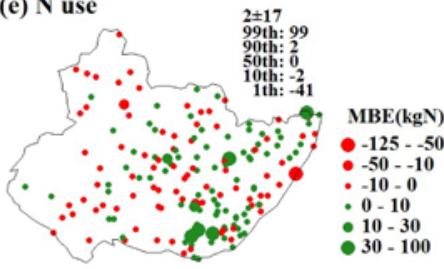

(h) Flowering to harvest

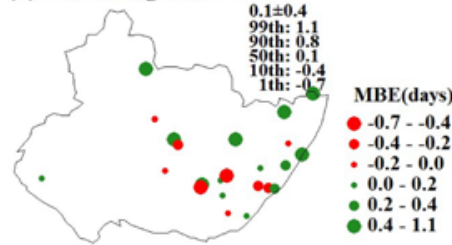

(k) Biomass

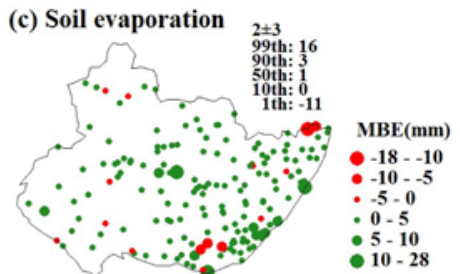

(f) Sowing date

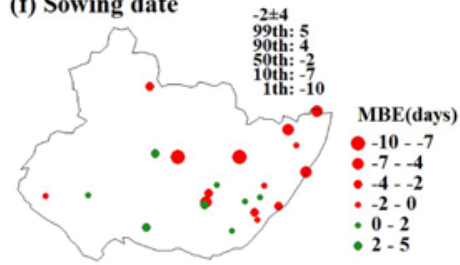

(i) Crop duration

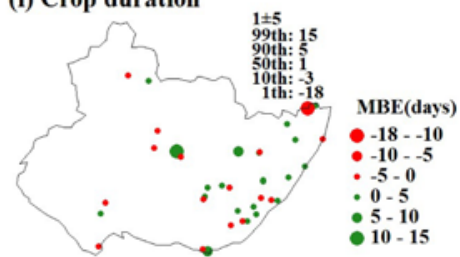

(l) Crop yield

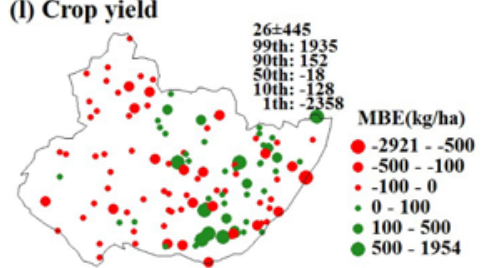




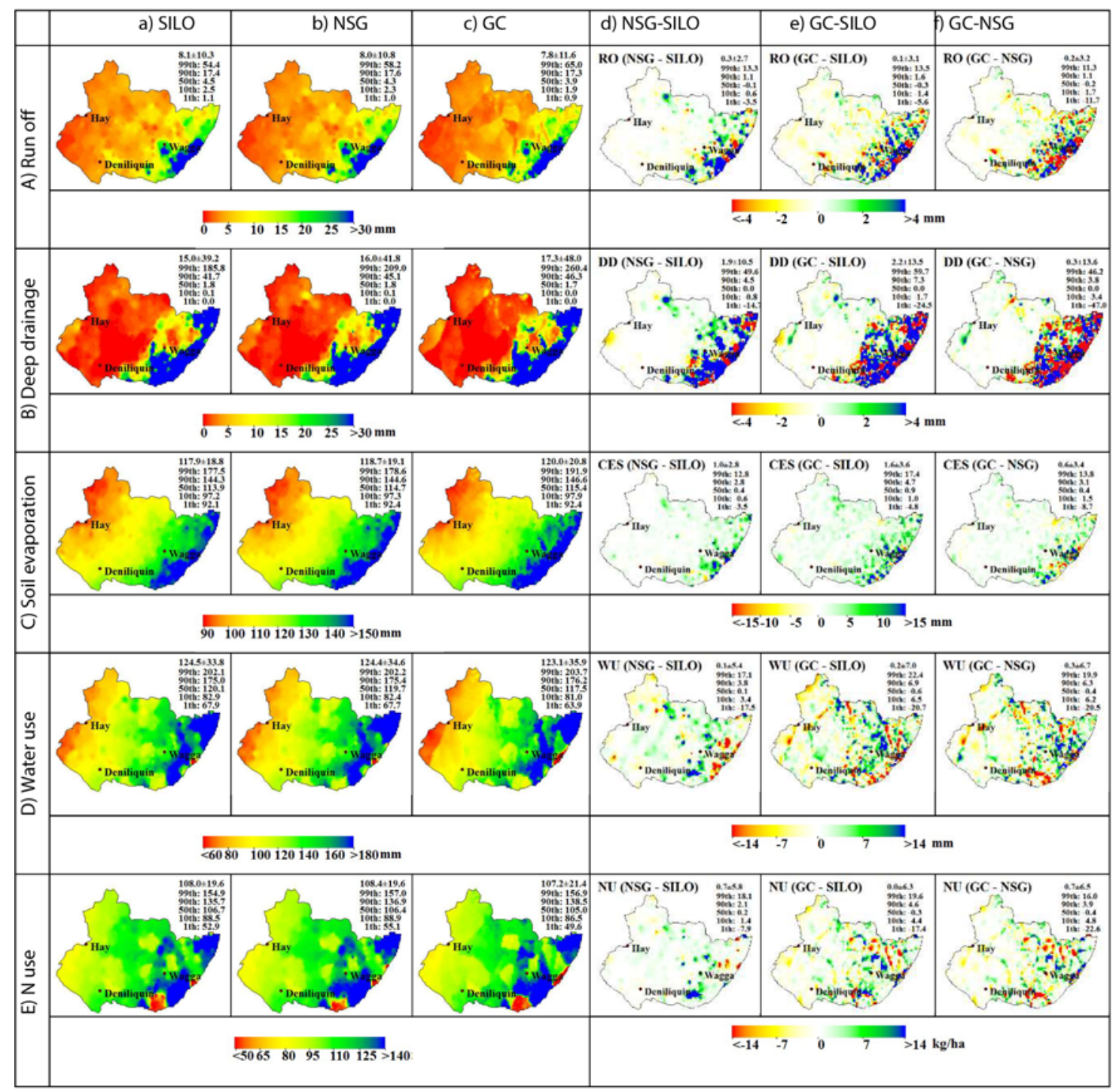




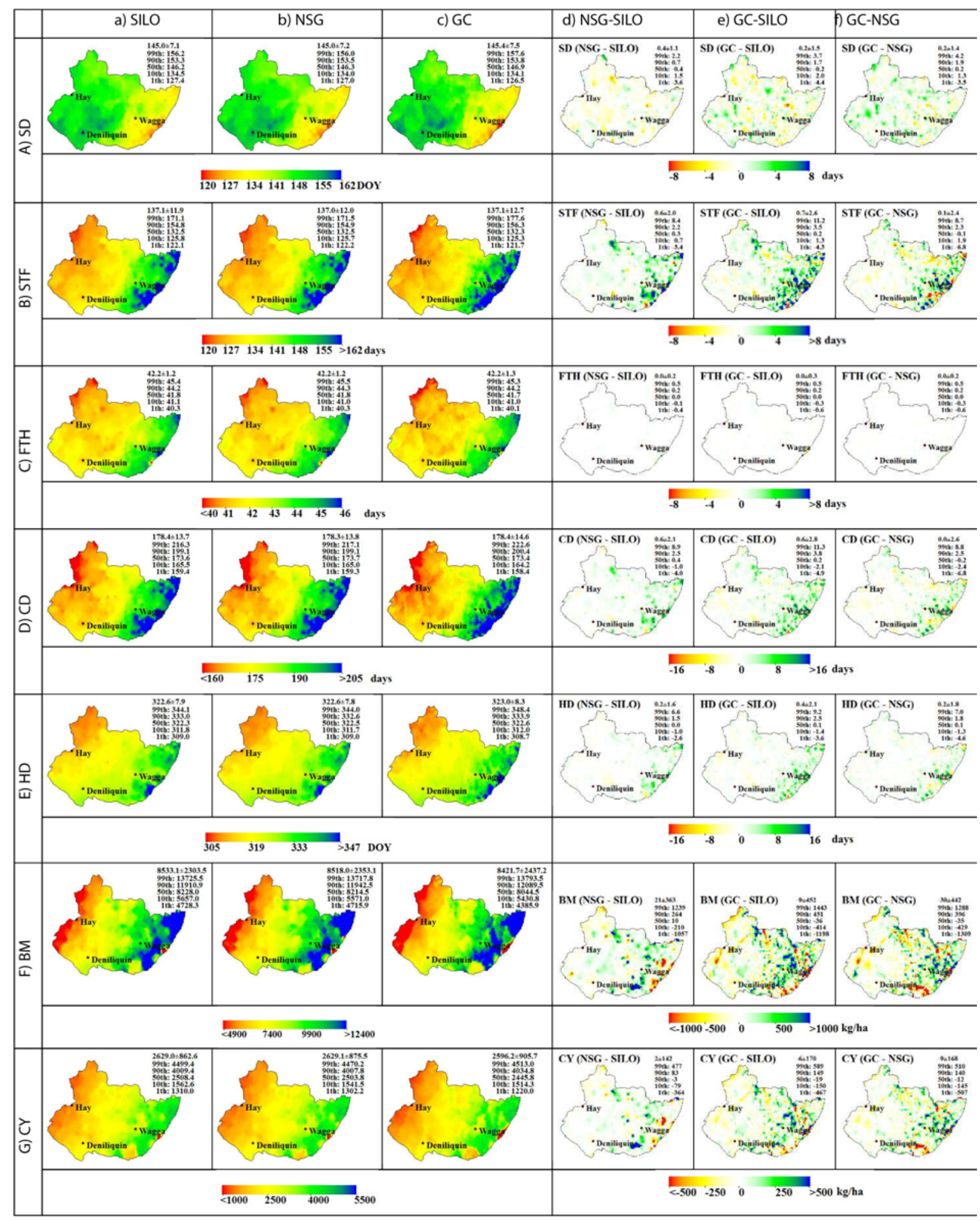




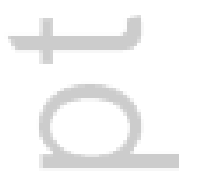

This article is protected by copyright. All rights reserved. 


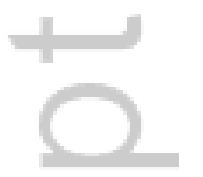


Table 4 Variance inflation factor (VIF) for all MBEs in all gridded climate variables and the stepwise regression associated with the 12 key APSIM outputs of wheat cropping system in Murray-Riverina cropping region. The values of the stepwise regression for exclusion of RI or RP are shown, except for the multiple linear regression of CY which shows the exclusion of MBEs of each climate variable. The variables in significant collinearity (mean \pm s.d. over the sites) are in bold. The regression was based on the sites with MBE of each variable $>0$ only.

\begin{tabular}{|c|c|c|c|c|c|c|c|}
\hline Variable & $\begin{array}{l}\begin{array}{l}\text { No of } \\
\text { site }\end{array} \\
\end{array}$ & Test variables & $T X^{\dagger}$ & $T I$ & $R n$ & $R I$ & $R P$ \\
\hline $\begin{array}{l}\text { Runoff } \\
\text { (RO) }\end{array}$ & 235 & $\begin{array}{c}\text { All } \\
\text { Excl. } R I \\
\text { Excl. } R P \\
\end{array}$ & $\begin{array}{r}\mathbf{2 1 . 9 5} \pm \mathbf{2 0 . 2 3} \\
2.35 \pm 1.49 \\
2.44 \pm 1.37 \\
\end{array}$ & $\begin{array}{r}\mathbf{2 1 . 5 5} \pm 2 \mathbf{2 0 . 6 3} \\
2.40 \pm 1.50 \\
2.49 \pm 1.37 \\
\end{array}$ & $\begin{array}{r}\mathbf{1 6 . 6 6} \pm \mathbf{1 2 . 4 6} \\
1.84 \pm 1.61 \\
1.88 \pm 2.71 \\
\end{array}$ & $\begin{array}{r}\mathbf{1 6 . 6 6} \pm \mathbf{1 2 . 4 6} \\
1.88 \pm 2.71 \\
\end{array}$ & $\begin{array}{r}\mathbf{1 6 . 9 9} \pm \mathbf{1 2 . 4 7} \\
1.70 \pm 1.21\end{array}$ \\
\hline $\begin{array}{l}\text { Deep drainage } \\
\text { (DD) }\end{array}$ & 92 & $\begin{array}{c}\text { All } \\
\text { Excl. RI } \\
\text { Excl. RP } \\
\end{array}$ & $\begin{array}{r}33.53 \pm 39.83 \\
3.35 \pm 1.94 \\
2.64 \pm 1.38 \\
\end{array}$ & $\begin{array}{r}\mathbf{3 3 . 5 3} \pm 39.83 \\
3.35 \pm 1.94 \\
2.64 \pm 1.38 \\
\end{array}$ & $\begin{array}{r}\mathbf{3 0 . 9 6} \pm \mathbf{3 8 . 2 9} \\
8.01 \pm 52.07 \\
2.18 \pm 2.08 \\
\end{array}$ & $\begin{array}{r}\mathbf{3 0 . 9 6} \pm 38.29 \\
2.18 \pm 2.08 \\
\end{array}$ & $\begin{array}{r}\mathbf{3 1 . 4 6} \pm 38.57 \\
2.56 \pm 2.40\end{array}$ \\
\hline $\begin{array}{l}\text { Soil } \\
\text { evaporation } \\
\text { (CES) }\end{array}$ & 253 & $\begin{array}{c}\text { All } \\
\text { Excl. } R I \\
\text { Excl. } R P \\
\end{array}$ & $\begin{array}{r}\mathbf{1 8 . 1 4} \pm \mathbf{1 7 . 9 9} \\
2.33 \pm 1.56 \\
2.11 \pm 1.15 \\
\end{array}$ & $\begin{array}{r}\mathbf{1 7 . 7 7} \pm \mathbf{1 7 . 8 2} \\
2.31 \pm 1.54 \\
2.08 \pm 1.14 \\
\end{array}$ & $\begin{array}{r}\mathbf{1 4 . 5 5} \pm \mathbf{1 1 . 0 6} \\
1.75 \pm 1.49 \\
1.99 \pm 3.86 \\
\end{array}$ & $\begin{array}{r}\mathbf{1 4 . 5 1} \pm \mathbf{1 1 . 0 5} \\
1.99 \pm 3.86 \\
\end{array}$ & $\begin{array}{r}\mathbf{1 4 . 5 6} \pm \mathbf{1 0 . 9 1} \\
1.70 \pm 1.38\end{array}$ \\
\hline $\begin{array}{l}\text { Water uptake } \\
\text { (WU) }\end{array}$ & 233 & $\begin{array}{c}\text { All } \\
\text { Excl. RI } \\
\text { Excl. RP } \\
\end{array}$ & $\begin{array}{r}\mathbf{1 8 . 9 8} \pm \mathbf{1 7 . 9 0} \\
2.48 \pm 1.54 \\
2.47 \pm 1.74 \\
\end{array}$ & $\begin{array}{r}\mathbf{1 8 . 9 8} \pm \mathbf{1 7 . 9 0} \\
2.46 \pm 1.53 \\
2.44 \pm 1.72 \\
\end{array}$ & $\begin{array}{r}\mathbf{1 3 . 9 5} \pm \mathbf{1 0 . 1 2} \\
2.88 \pm \mathbf{1 6 . 6 1} \\
2.25 \pm 4.27 \\
\end{array}$ & $\begin{array}{r}\mathbf{1 3 . 9 5} \pm \mathbf{1 0 . 1 2} \\
2.25 \pm 4.26 \\
\end{array}$ & $\begin{array}{r}\mathbf{1 3 . 9 7} \pm \mathbf{1 0 . 0 1} \\
1.61 \pm 1.20\end{array}$ \\
\hline $\begin{array}{l}\text { N uses } \\
\text { (NU) }\end{array}$ & 229 & $\begin{array}{c}\text { All } \\
\text { Excl. RI } \\
\text { Excl. RP }\end{array}$ & $\begin{array}{r}\mathbf{1 8 . 8 2} \pm \mathbf{1 8 . 8 4} \\
2.45 \pm 1.62 \\
2.35 \pm 1.34 \\
\end{array}$ & $\begin{array}{r}\mathbf{1 8 . 8 2} \pm \mathbf{1 8 . 8 4} \\
2.45 \pm 1.62 \\
2.35 \pm 1.34 \\
\end{array}$ & $\begin{array}{r}\mathbf{1 3 . 9 0} \pm \mathbf{1 0 . 0 6} \\
2.01 \pm 5.27 \\
1.78 \pm 2.92 \\
\end{array}$ & $\begin{array}{r}\mathbf{1 3 . 9 0} \pm \mathbf{1 0 . 0 6} \\
1.78 \pm 2.91 \\
\end{array}$ & $\begin{array}{r}\mathbf{1 4 . 1 0} \pm \mathbf{9 . 9 5} \\
1.63 \pm 1.20\end{array}$ \\
\hline $\begin{array}{l}\text { Sowing date } \\
\text { (SD) }\end{array}$ & 44 & $\begin{array}{c}\text { All } \\
\text { Excl. RI } \\
\text { Excl. RP } \\
\end{array}$ & $\begin{array}{r}\mathbf{2 6 . 0 5} \pm \mathbf{2 1 . 3 3} \\
2.64 \pm 2.40 \\
2.74 \pm 2.98 \\
\end{array}$ & $\begin{array}{r}\mathbf{2 6 . 4 7} \pm 21.44 \\
2.65 \pm 2.42 \\
2.74 \pm 3.01 \\
\end{array}$ & $\begin{array}{r}26.05 \pm 21.33 \\
2.64 \pm 2.40 \\
2.74 \pm 2.98 \\
\end{array}$ & $\begin{array}{r}\mathbf{2 6 . 0 5} \pm \mathbf{2 1 . 3 3} \\
2.74 \pm 2.98 \\
\end{array}$ & $\begin{array}{r}\mathbf{2 6 . 0 5} \pm \mathbf{2 1 . 3 3} \\
2.64 \pm 2.40\end{array}$ \\
\hline $\begin{array}{l}\text { Sowing to } \\
\text { Flowering } \\
\text { (STF) }\end{array}$ & 75 & $\begin{array}{c}\text { All } \\
\text { Excl. RI } \\
\text { Excl. RP } \\
\end{array}$ & $\begin{array}{r}\mathbf{2 2 . 6 8} \pm \mathbf{1 7 . 7 2} \\
2.69 \pm 1.62 \\
2.62 \pm 1.77 \\
\end{array}$ & $\begin{array}{r}\mathbf{2 2 . 6 8} \pm \mathbf{1 7 . 7 2} \\
2.69 \pm 1.62 \\
2.62 \pm 1.77 \\
\end{array}$ & $\begin{array}{r}\mathbf{2 2 . 4 8} \pm \mathbf{1 7 . 6 8} \\
2.69 \pm 1.62 \\
2.62 \pm 1.77 \\
\end{array}$ & $\begin{array}{r}\mathbf{2 2 . 4 8} \pm \mathbf{1 7 . 6 8} \\
2.62 \pm 1.77 \\
\end{array}$ & $\begin{array}{r}\mathbf{2 2 . 4 8} \pm \mathbf{1 7 . 6 8} \\
2.69 \pm 1.62\end{array}$ \\
\hline $\begin{array}{l}\text { Flowering to } \\
\text { harvest } \\
(\mathrm{FTH})\end{array}$ & 32 & $\begin{array}{c}\text { All } \\
\text { Excl. RI } \\
\text { Excl. RP }\end{array}$ & $\begin{array}{r}\mathbf{2 0 . 5 5} \pm \mathbf{1 8 . 0 9} \\
2.81 \pm 1.67 \\
2.99 \pm 2.57 \\
\end{array}$ & $\begin{array}{r}\mathbf{2 0 . 5 5} \pm \mathbf{1 8 . 0 9} \\
2.81 \pm 1.67 \\
2.99 \pm 2.57 \\
\end{array}$ & $\begin{array}{r}\mathbf{2 0 . 5 5} \pm \mathbf{1 8 . 0 9} \\
2.81 \pm 1.67 \\
2.99 \pm 2.57 \\
\end{array}$ & $\begin{array}{r}\mathbf{2 0 . 5 5} \pm \mathbf{1 8 . 0 9} \\
2.99 \pm 2.57 \\
\end{array}$ & $\begin{array}{r}\mathbf{2 0 . 5 5} \pm \mathbf{1 8 . 0 9} \\
2.81 \pm 1.67\end{array}$ \\
\hline $\begin{array}{l}\text { Crop duration } \\
\text { (CD) }\end{array}$ & 74 & $\begin{array}{c}\text { All } \\
\text { Excl. RI } \\
\text { Excl. RP } \\
\end{array}$ & $\begin{array}{r}\mathbf{2 1 . 6 7} \pm \mathbf{1 8 . 9 7} \\
2.78 \pm 1.71 \\
2.58 \pm 1.84 \\
\end{array}$ & $\begin{array}{r}\mathbf{2 1 . 6 7} \pm \mathbf{1 8 . 9 7} \\
2.78 \pm 1.71 \\
2.58 \pm 1.84 \\
\end{array}$ & $\begin{array}{r}\mathbf{2 1 . 6 7} \pm \mathbf{1 8 . 9 7} \\
2.78 \pm 1.71 \\
2.58 \pm 1.84 \\
\end{array}$ & $\begin{array}{r}21.67 \pm 18.97 \\
2.58 \pm 1.84 \\
\end{array}$ & $\begin{array}{r}21.67 \pm 18.97 \\
2.78 \pm 1.71\end{array}$ \\
\hline $\begin{array}{l}\text { Harvesting } \\
\text { date } \\
\text { (HD) }\end{array}$ & 69 & $\begin{array}{c}\text { All } \\
\text { Excl. RI } \\
\text { Excl. RP }\end{array}$ & $\begin{array}{r}\mathbf{2 2 . 2 9} \pm \mathbf{2 1 . 9 2} \\
2.66 \pm 1.64 \\
2.67 \pm 1.95 \\
\end{array}$ & $\begin{array}{r}\mathbf{2 2 . 4 8} \pm 22.04 \\
2.67 \pm 1.65 \\
2.67 \pm 1.96 \\
\end{array}$ & $\begin{array}{r}\mathbf{2 2 . 2 9} \pm \mathbf{2 1 . 9 2} \\
2.66 \pm 1.64 \\
2.67 \pm 1.95 \\
\end{array}$ & $\begin{array}{r}\mathbf{2 2 . 2 9} \pm \mathbf{2 1 . 9 2} \\
2.67 \pm 1.95 \\
\end{array}$ & $\begin{array}{r}22.29 \pm 21.92 \\
2.66 \pm 1.64\end{array}$ \\
\hline $\begin{array}{l}\text { Biomass } \\
(\mathrm{BM})\end{array}$ & 240 & $\begin{array}{c}\text { All } \\
\text { Excl. } R I \\
\text { Excl. } R P\end{array}$ & $\begin{array}{r}\mathbf{1 8 . 5 6} \pm \mathbf{1 7 . 7 2} \\
2.49 \pm 1.56 \\
2.48 \pm 1.74 \\
\end{array}$ & $\begin{array}{r}\mathbf{1 8 . 5 6} \pm \mathbf{1 7 . 7 2} \\
2.49 \pm 1.56 \\
2.45 \pm 1.72 \\
\end{array}$ & $\begin{array}{r}\mathbf{1 4 . 3 9} \pm \mathbf{1 0 . 1 8} \\
2.63 \pm \mathbf{1 3 . 8 8} \\
2.23 \pm 4.24 \\
\end{array}$ & $\begin{array}{r}\mathbf{1 4 . 3 5} \pm \mathbf{1 0 . 1 7} \\
2.22 \pm 4.23 \\
\end{array}$ & $\begin{array}{r}\mathbf{1 4 . 3 7} \pm \mathbf{1 0 . 0 6} \\
1.61 \pm 1.20\end{array}$ \\
\hline $\begin{array}{l}\text { Crop yield } \\
(\mathrm{CY})\end{array}$ & 237 & $\begin{array}{c}\text { All } \\
\text { Excl. } T X \\
\text { Excl. } T I \\
\text { Excl. } R n \\
\text { Excl. } R I \\
\text { Excl. } R P\end{array}$ & $\begin{array}{r}\mathbf{1 7 . 5 7} \pm \mathbf{1 7 . 3 9} \\
\\
\mathbf{1 2 . 3 0} \pm \mathbf{6 . 4 1} \\
7.62 \pm 5.42 \\
2.48 \pm 1.58 \\
2.50 \pm 1.76 \\
\end{array}$ & $\begin{array}{r}\mathbf{1 7 . 5 7} \pm \mathbf{1 7 . 3 9} \\
\mathbf{1 4 . 5 9} \pm \mathbf{9 . 0 5} \\
\\
7.46 \pm 5.41 \\
2.46 \pm 1.56 \\
2.47 \pm 1.74\end{array}$ & $\begin{array}{r}\mathbf{1 4 . 0 1} \pm \mathbf{1 0 . 1 3} \\
\mathbf{1 3 . 6 1} \pm \mathbf{8 . 4 7} \\
\mathbf{1 3 . 3 1} \pm \mathbf{8 . 1 5} \\
\\
2.19 \pm 7.54 \\
2.08 \pm 4.06 \\
\end{array}$ & $\begin{array}{r}14.01 \pm 10.13 \\
13.61 \pm 8.47 \\
13.31 \pm 8.15 \\
7.48 \pm 5.52 \\
\\
2.09 \pm 4.05 \\
\end{array}$ & $\begin{array}{r}14.02 \pm 9.98 \\
13.58 \pm 8.17 \\
13.27 \pm 7.82 \\
7.74 \pm 5.31 \\
1.62 \pm 1.21\end{array}$ \\
\hline
\end{tabular}

${ }^{+}$The test variable means the test whether this variable, e.g., TX, has collinearity with other variables, i.e., TI, Rn, RI and/or RP. 
Table 5 The coefficients and statistics of the multiple linear least squared regression of biases in APSIMsimulated outputs as a function of the bias in climate variables (Eq. 4, without radiation). The mean coefficient and the standard deviation ( \pm s.d.) are shown. The number of these sites with significance $(\mathrm{P}<0.05)$ being greater than $1 / 3$, but less than $2 / 3$ is marked in italics and more than $2 / 3$ in bold. The regression was based on the sites with MBE of each variable $>0$ only.

\begin{tabular}{|c|c|c|c|c|c|c|c|}
\hline Variable & $\begin{array}{l}\text { No of } \\
\text { sites }\end{array}$ & $\begin{array}{l}\mathrm{MBE}_{\mathrm{TX}} \\
\mathrm{b}\left({ }^{\circ} \mathrm{C}^{-1}\right)\end{array}$ & $\begin{array}{l}\mathrm{MBE}_{\mathrm{TI}} \\
\mathrm{c}\left({ }^{\circ} \mathrm{C}^{-1}\right)\end{array}$ & $\begin{array}{c}\mathrm{MBE}_{\mathrm{Rn}} \\
\mathrm{d}\left(\mathrm{mm}^{-1}\right)\end{array}$ & $\begin{array}{c}\mathrm{MBE}_{\mathrm{RI}} \\
\mathrm{e}\left(\left(\mathrm{mm} \mathrm{rain}^{-1}\right)^{-1}\right)\end{array}$ & $\begin{array}{l}\mathrm{MBE}_{\mathrm{RP}} \\
\mathrm{f}\left(\%^{-1}\right)\end{array}$ & $\begin{array}{c}\mathrm{R}^{2} \\
\left(\min \mathrm{R}^{2} \sim \max \mathrm{R}^{2}\right)\end{array}$ \\
\hline $\mathrm{MBE}_{\mathrm{RO}}$ & 235 & $1.37 \pm 2.58$ & $1.33 \pm 4.60$ & $0.09 \pm 0.09$ & & $-0.13 \pm 0.32$ & $0.45 \pm 0.22(0.05 \sim 0.95)$ \\
\hline$(\mathrm{mm})$ & & $1.58 \pm 2.16$ & $0.57 \pm 4.28$ & $0.08 \pm 0.09$ & $0.01 \pm 0.02$ & & $0.45 \pm 0.21(0.05 \sim 0.97)$ \\
\hline $\mathrm{MBE}_{\mathrm{DD}}$ & 92 & $-10.46 \pm 52.91$ & $0.27 \pm 48.52$ & $0.62 \pm 0.32$ & & $0.08 \pm 1.74$ & $0.76 \pm 0.18(0.20 \sim 1.00)$ \\
\hline$(\mathrm{mm})$ & & $-6.74 \pm 45.73$ & $1.16 \pm 54.80$ & $0.64 \pm 0.30$ & $-0.01 \pm 0.11$ & & $0.75 \pm 0.19(0.19 \sim 1.00)$ \\
\hline $\mathrm{MBE}_{\mathrm{CES}}$ & 253 & $0.70 \pm 11.50$ & $1.89 \pm 10.53$ & $0.10 \pm 0.15$ & & $0.27 \pm 0.29$ & $0.49 \pm 0.23(0.07 \sim 0.98)$ \\
\hline$(\mathrm{mm})$ & & $1.05 \pm 11.02$ & $2.79 \pm 11.73$ & $0.12 \pm 0.16$ & $-0.01 \pm 0.03$ & & $0.49 \pm 0.23(0.05 \sim 0.98)$ \\
\hline $\mathrm{MBE}_{W U}$ & 233 & $4.48 \pm 24.23$ & $-8.89 \pm 21.81$ & $0.21 \pm 0.32$ & & $-0.09 \pm 1.16$ & $0.47 \pm 0.21(0.01 \sim 1.00)$ \\
\hline$(\mathrm{mm})$ & & $2.81 \pm 21.50$ & $-10.60 \pm 29.65$ & $0.17 \pm 0.35$ & $0.02 \pm 0.10$ & & $0.47 \pm 0.21(0.01 \sim 1.00)$ \\
\hline $\mathrm{MBE}_{\mathrm{NU}}$ & 229 & $0.55 \pm 29.26$ & $-7.75 \pm 30.19$ & $0.10 \pm 0.20$ & & $0.02 \pm 1.29$ & $0.38 \pm 0.21(0.01 \sim 0.99)$ \\
\hline$\left(\mathrm{kg} \mathrm{ha}^{-1}\right)$ & & $0.58 \pm 28.87$ & $-10.45 \pm 38.94$ & $0.09 \pm 0.24$ & $0.00 \pm 0.08$ & & $0.38 \pm 0.21(0.01 \sim 0.99)$ \\
\hline $\mathrm{MBE}_{\mathrm{SD}}$ & 44 & $13.81 \pm 32.84$ & $19.22 \pm 48.56$ & $-0.07 \pm 0.14$ & & $0.07 \pm 0.46$ & $0.92 \pm 0.06(0.69 \sim 1.00)$ \\
\hline (doy) & & $12.94 \pm 31.15$ & $20.56 \pm 45.24$ & $-0.06 \pm 0.16$ & $0.01 \pm 0.03$ & & $0.92 \pm 0.06(0.69 \sim 1.00)$ \\
\hline $\mathrm{MBE}_{\mathrm{STF}}$ & 75 & $-9.50 \pm 12.45$ & $-6.03 \pm 18.65$ & $0.03 \pm 0.08$ & & $-0.07 \pm 0.37$ & $0.91 \pm 0.07$ (0.65 0.99) \\
\hline (days) & & $-9.27 \pm 11.84$ & $-6.50 \pm 17.58$ & $0.04 \pm 0.10$ & $-0.01 \pm 0.03$ & & $0.91 \pm 0.07(0.65 \sim 0.99)$ \\
\hline $\mathrm{MBE}_{\mathrm{FTH}}$ & 32 & $-2.03 \pm 3.61$ & $-1.21 \pm 5.05$ & $0.01 \pm 0.03$ & & $-0.03 \pm 0.14$ & $0.72 \pm 0.20(0.14 \sim 0.97)$ \\
\hline (days) & & $-1.95 \pm 3.74$ & $-1.61 \pm 5.03$ & $0.01 \pm 0.04$ & $0.00 \pm 0.01$ & & $0.71 \pm 0.20(0.15 \sim 0.97)$ \\
\hline $\mathrm{MBE}_{\mathrm{CD}}$ & 74 & $-12.21 \pm 25.54$ & $-3.97 \pm 40.81$ & $0.08 \pm 0.20$ & & $-0.06 \pm 0.49$ & $0.91 \pm 0.10(0.24 \sim 0.99)$ \\
\hline (Days) & & $-11.47 \pm 24.30$ & $-4.97 \pm 36.48$ & $0.08 \pm 0.21$ & $-0.01 \pm 0.04$ & & $0.91 \pm 0.10(0.24 \sim 0.99)$ \\
\hline $\mathrm{MBE}_{\mathrm{HD}}$ & 69 & $7.68 \pm 9.22$ & $2.11 \pm 11.00$ & $-0.01 \pm 0.12$ & & $-0.01 \pm 0.47$ & $0.84 \pm 0.12(0.44 \sim 1.00)$ \\
\hline (doy) & & $7.66 \pm 8.40$ & $1.61 \pm 9.64$ & $-0.01 \pm 0.13$ & $0.01 \pm 0.03$ & & $0.85 \pm 0.11(0.51 \sim 1.00)$ \\
\hline $\mathrm{MBE}_{\mathrm{BM}}$ & 240 & $-513.97 \pm 1573.93$ & $-541.20 \pm 1669.48$ & $14.41 \pm 22.32$ & & $-5.22 \pm 77.34$ & $0.47 \pm 0.22(0.02 \sim 1.00)$ \\
\hline$\left(\mathrm{kg} \mathrm{ha}^{-1}\right)$ & & $-559.93 \pm 1415.69$ & $-664.98 \pm 2183.55$ & $12.75 \pm 24.07$ & $0.67 \pm 6.11$ & & $0.48 \pm 0.22(0.02 \sim 1.00)$ \\
\hline $\mathrm{MBE}_{\mathrm{CY}}$ & 237 & $-137.41 \pm 578.63$ & $-129.92 \pm 544.37$ & $5.84 \pm 8.67$ & & $-0.64 \pm 30.64$ & $0.46 \pm 0.22(0.01 \sim 0.99)$ \\
\hline$\left(\mathrm{kg} \mathrm{ha}^{-1}\right)$ & & $-150.53 \pm 518.99$ & $-157.16 \pm 710.37$ & $5.62 \pm 9.21$ & $0.11 \pm 2.18$ & & $0.47 \pm 0.22(0.01 \sim 0.99)$ \\
\hline
\end{tabular}


Table 1 Proportion (\%) of SILO sites that have significant different climate variables between the site observations and the interpolated values for the site located grids.

\begin{tabular}{lcccc}
\hline Variables & Daily & Monthly & Yearly & Growing season \\
\hline Solar radiation (SR) & 11.4 & 3.5 & 2.2 & 13.2 \\
Max temperature (TX) & 22.7 & 18.9 & 15.7 & 16.8 \\
Min temperature (TI) & 26.8 & 25.1 & 16.0 & 16.2 \\
Rainfall (Rn) & 59.5 & 57.8 & 53.5 & 47.0 \\
Rainfall intensity (RI) & & 78.4 & 76.8 & 76.2 \\
Rainfall probability (RP) & & 76.0 & 73.8 & 73.5 \\
\hline
\end{tabular}


Table 2: Statistical tests of the differences between the interpolated and observed climate variables and the differences between the spatial interpolated values in each pair of these based on site observations, the sitelocated grids and the 5-km grids in the growing season period.

\begin{tabular}{lrrrrrrr}
\hline \multicolumn{1}{c}{ Data source } & no & $\begin{array}{r}\text { SR } \\
\left(\mathrm{MJ} \mathrm{m}^{-2}\right)\end{array}$ & $\begin{array}{r}\mathrm{TX} \\
\left({ }^{\circ} \mathrm{C}\right)\end{array}$ & $\begin{array}{r}\mathrm{TI} \\
\left({ }^{\circ} \mathrm{C}\right)\end{array}$ & $\begin{array}{r}\mathrm{Rn} \\
(\mathrm{mm})\end{array}$ & $\begin{array}{r}\mathrm{RI} \\
\left(\mathrm{mm} \mathrm{rn}^{-1}\right)\end{array}$ & $\begin{array}{r}\mathrm{RP} \\
(\%)\end{array}$ \\
\hline & & \multicolumn{7}{c}{$\mathrm{MAE}$} \\
SILO vs NSG & 370 & 0.00 & 0.00 & 0.00 & -2.56 & 0.63 & -3.46 \\
SILO vs NSG & 4741 & 0.00 & 0.00 & 0.00 & -1.41 & 0.80 & -2.92 \\
NSG vs GC & 4741 & 0.00 & 0.04 & 0.03 & -0.67 & 0.38 & -2.02 \\
SILO vs GC & 4741 & 0.00 & 0.04 & 0.02 & -2.07 & 1.18 & -4.94 \\
& & \multicolumn{7}{c}{ RMSE } \\
SILO vs NSG & 370 & 0.08 & 0.12 & 0.09 & 15.06 & 0.88 & 4.67 \\
SILO vs NSG & 4741 & 0.01 & 0.10 & 0.07 & 10.27 & 0.94 & 3.43 \\
NSG vs GC & 4741 & 0.04 & 0.35 & 0.22 & 26.47 & 0.49 & 2.44 \\
SILO vs GC & 4741 & 0.04 & 0.36 & 0.24 & 26.70 & 1.33 & 5.50 \\
& & \multicolumn{7}{c}{ NSE (no units) } & & & \\
SILO vs NSG & 370 & 0.88 & 0.97 & 0.96 & 0.94 & 0.40 & 0.39 \\
SILO vs NSG & 4741 & 1.00 & 0.99 & 0.98 & 0.96 & 0.03 & 0.24 \\
NSG vs GC & 4741 & 0.92 & 0.82 & 0.86 & 0.89 & 0.34 & 0.47 \\
SILO vs GC & 4741 & 0.92 & 0.82 & 0.85 & 0.88 & -0.43 & -0.30 \\
\hline
\end{tabular}




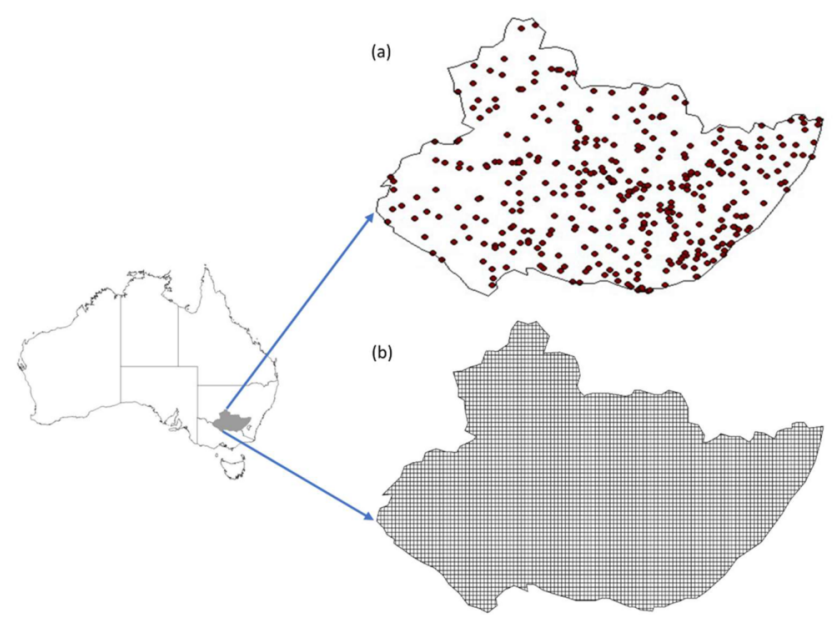

JOC_6371_figure1.tif

This article is protected by copyright. All rights reserved. 

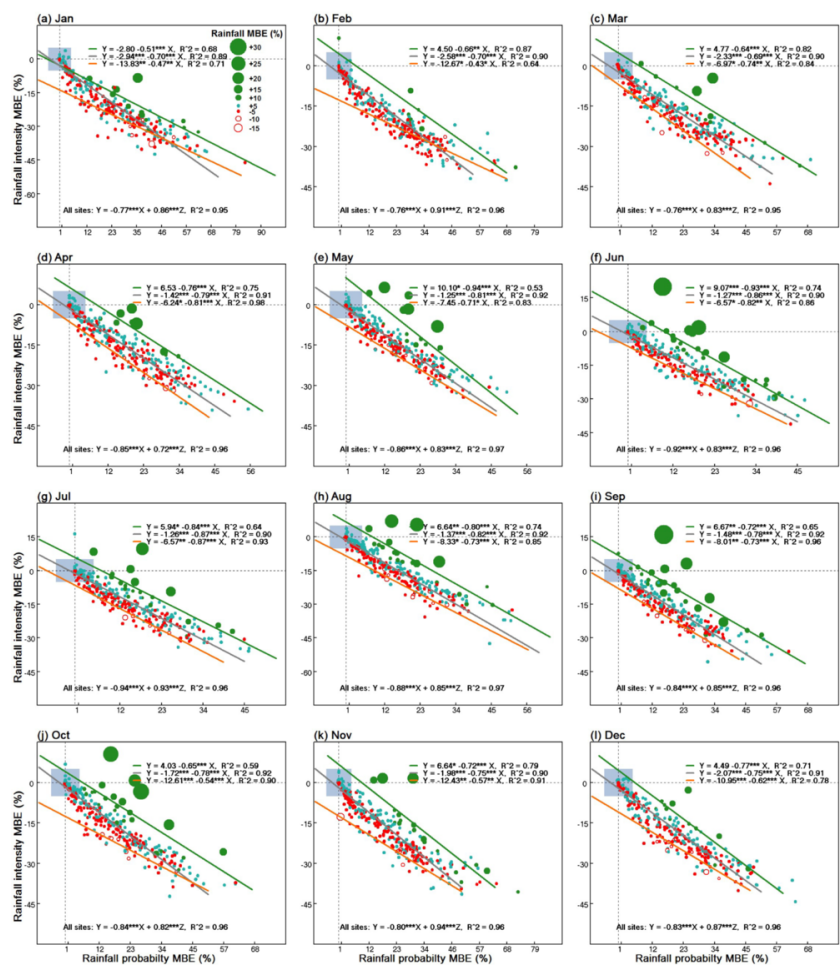

(1) Dec

JOC_6371_figure2.tif

This article is protected by copyright. All rights reserved. 


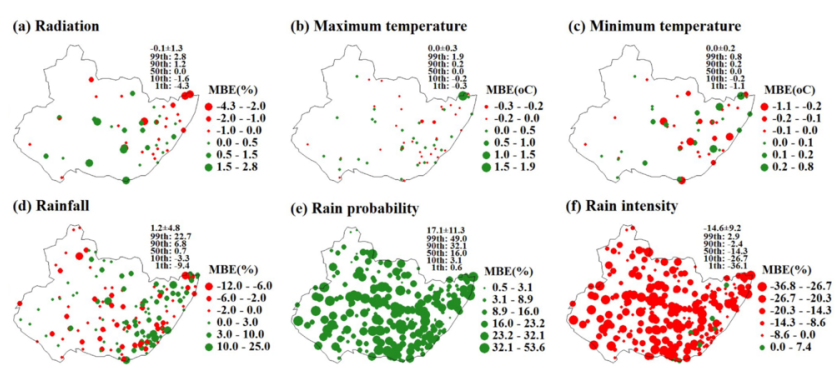

J0C_6371_figure3.tif

This article is protected by copyright. All rights reserved. 


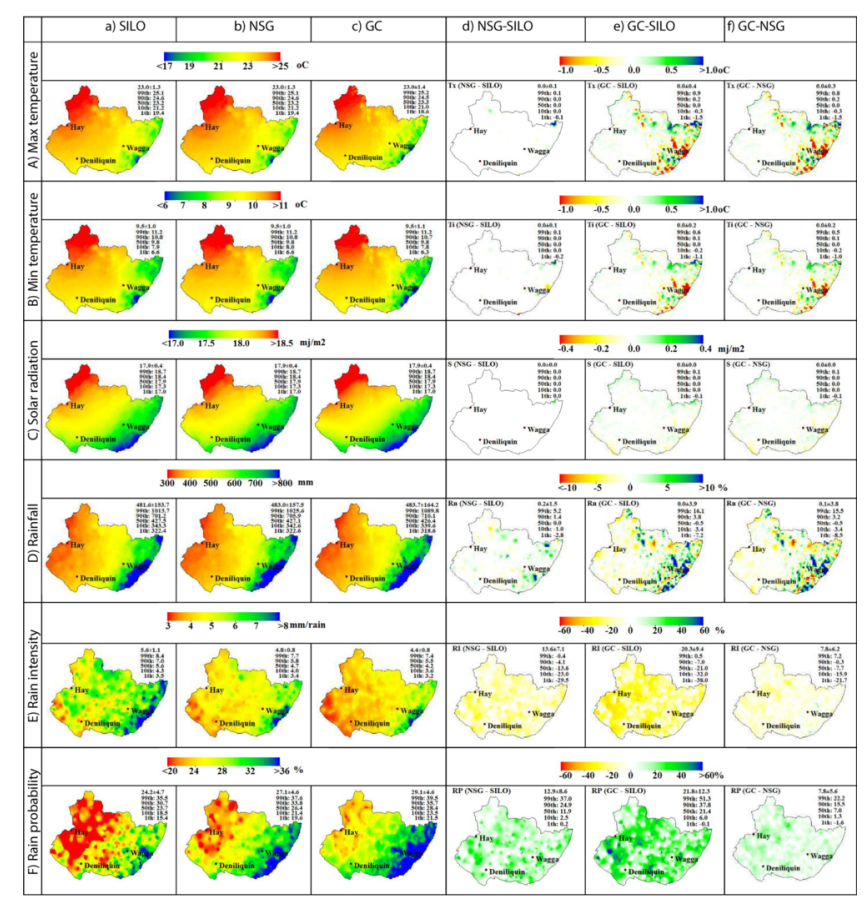

JOC_6371_figure4.tif

This article is protected by copyright. All rights reserved. 


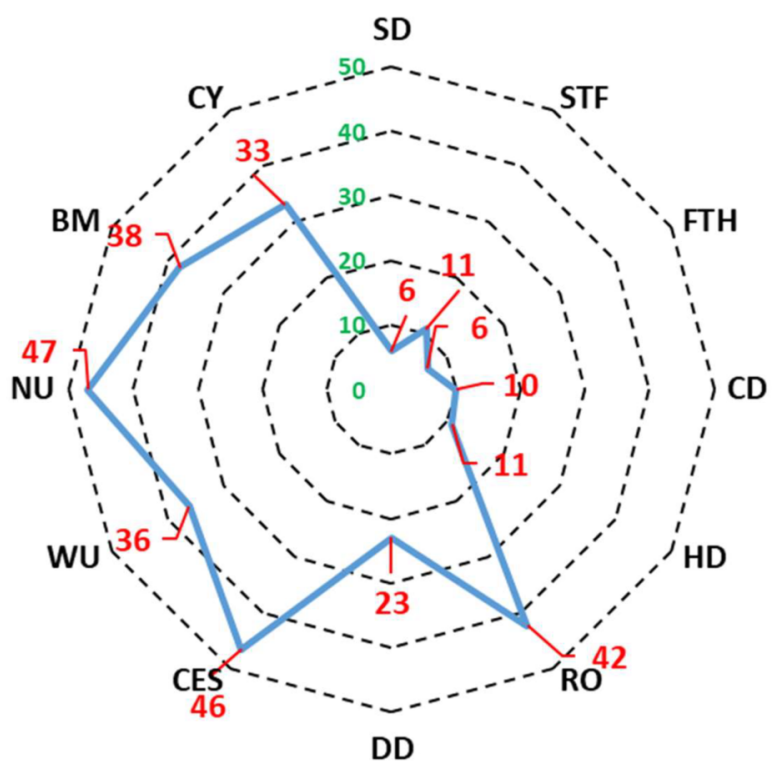

JOC_6371_figure5.tif 


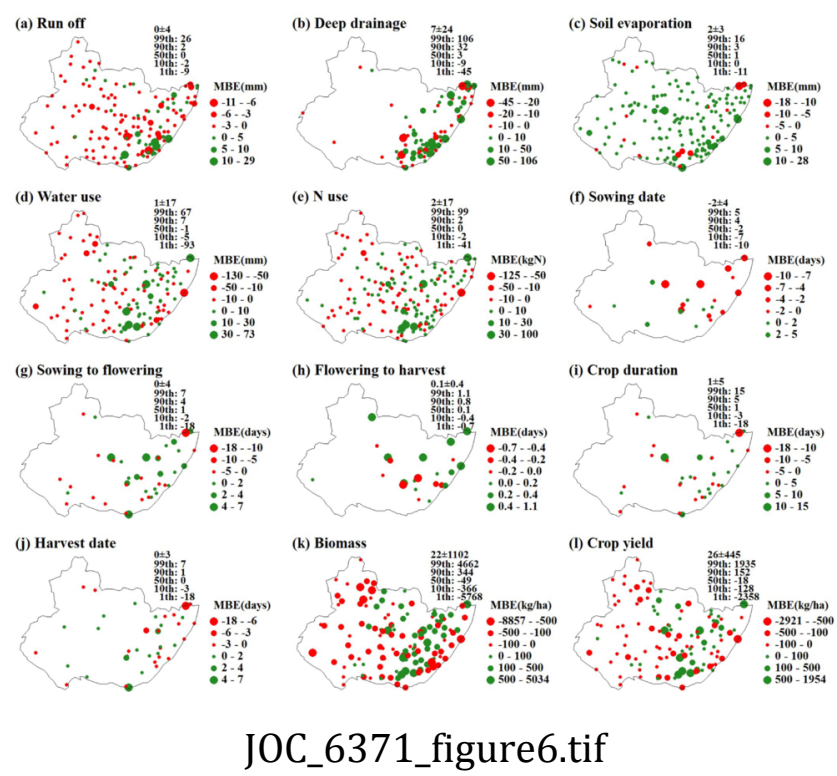

This article is protected by copyright. All rights reserved. 


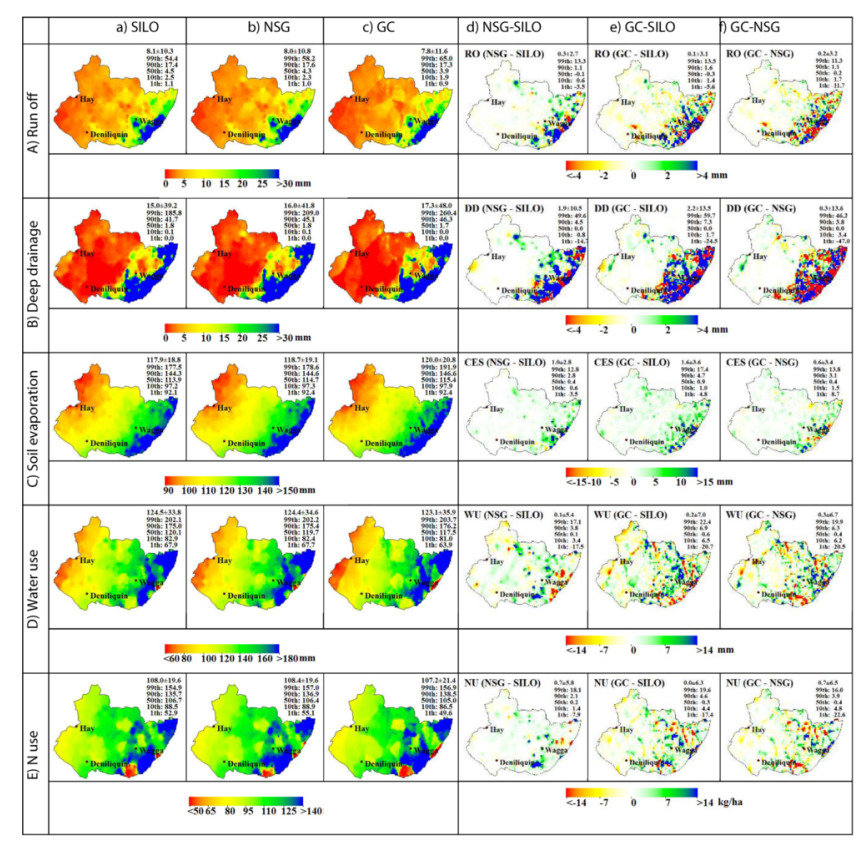

JOC_6371_figure7.tif

This article is protected by copyright. All rights reserved. 


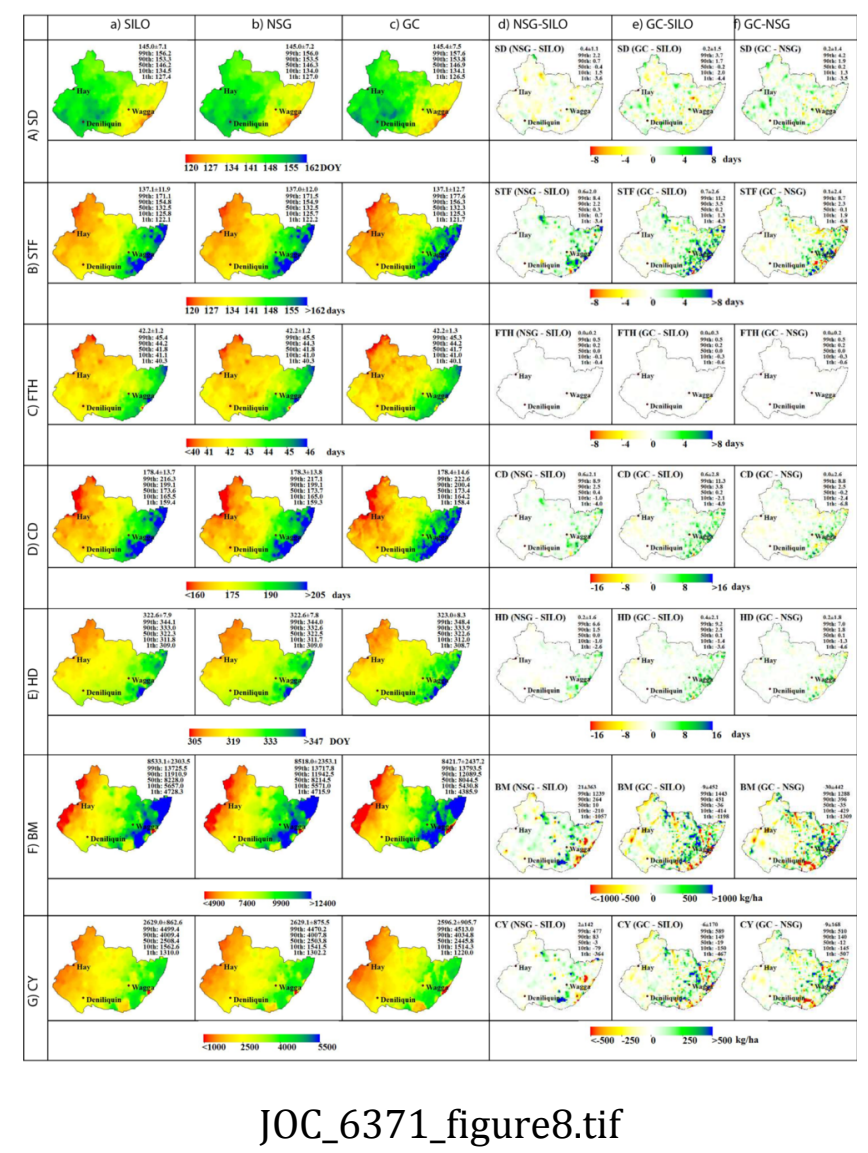

This article is protected by copyright. All rights reserved. 


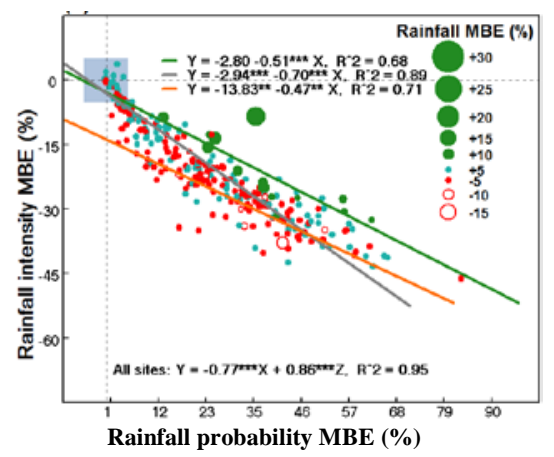

Article title:

The implication of spatial interpolated climate data on biophysical modelling in agricultural systems

De Li Liu, Fei Ji, Bin Wang, Cathy Waters, Puyu Feng, Rebecca Darbyshire

Our study showed that the major differences between gridded and observed climate datasets were for rainfall variables. Interpolated gridded data tended to have larger rainfall frequency and smaller rainfall intensity, leading to lower surface runoff and higher soil evaporation that caused less plant water uses and less nitrogen uptake, and ultimately resulted in biases in simulated crop biomass and yield. Our study suggested that applying agricultural models with observed data and interpolating these results spatially may be the optimal approach to minimise the biases in production modelling outputs and reduce computing time and storage. 
Table 1 Proportion (\%) of SILO sites that have significant different climate variables between the site observations and the interpolated values for the site located grids.

\begin{tabular}{lcccc}
\hline Variables & Daily & Monthly & Yearly & Growing season \\
\hline Solar radiation (SR) & 11.4 & 3.5 & 2.2 & 13.2 \\
Max temperature (TX) & 22.7 & 18.9 & 15.7 & 16.8 \\
Min temperature (TI) & 26.8 & 25.1 & 16.0 & 16.2 \\
Rainfall (Rn) & 59.5 & 57.8 & 53.5 & 47.0 \\
Rainfall intensity (RI) & & 78.4 & 76.8 & 76.2 \\
Rainfall probability (RP) & & 76.0 & 73.8 & 73.5 \\
\hline
\end{tabular}


Table 3 Statistical tests of the differences between the APSIM outputs resulting from observed and interpolated climate variables and the differences between the interpolated spatial APSIM-output maps resulting from the observed climate variables, interpolated climate variables and the 5-km gridded climate variables. The acronyms are shown in Table 4.

\begin{tabular}{|c|c|c|c|c|c|c|c|c|c|c|c|c|}
\hline Data source (no) & $\begin{array}{l}\mathrm{RO} \\
(\mathrm{mm})\end{array}$ & $\begin{array}{l}\begin{array}{l}\mathrm{DD} \\
(\mathrm{mm})\end{array} \\
\end{array}$ & $\begin{array}{l}\begin{array}{l}\text { CES } \\
(\mathrm{mm})\end{array} \\
\end{array}$ & $\begin{array}{l}\begin{array}{l}\text { WU } \\
(\mathrm{mm})\end{array} \\
\end{array}$ & $\begin{array}{l}\text { NU } \\
\left(\mathrm{kg} \mathrm{ha}^{-1}\right)\end{array}$ & $\begin{array}{l}\text { SD } \\
\text { (days) }\end{array}$ & $\begin{array}{l}\text { STF } \\
\text { (days) }\end{array}$ & $\begin{array}{l}\text { FTH } \\
\text { (days) }\end{array}$ & $\begin{array}{l}\text { CD } \\
\text { (days) }\end{array}$ & $\begin{array}{l}\text { HD } \\
\text { (days) }\end{array}$ & $\begin{array}{l}\text { BM } \\
\left(\mathrm{kg} \mathrm{ha}^{-1}\right)\end{array}$ & $\begin{array}{l}\text { CY } \\
\left(\mathrm{kg} \mathrm{ha}^{-1}\right)\end{array}$ \\
\hline \multicolumn{13}{|c|}{ MAE } \\
\hline SILO vs NSG (370) & 0.00 & -1.69 & -0.84 & -0.19 & -0.69 & 0.00 & 0.01 & 0.01 & 0.01 & 0.01 & -4.64 & -6.80 \\
\hline $\mathrm{I}_{\text {SILO }}$ vs $\mathrm{I}_{\text {NSG }}(4741)$ & -0.28 & -1.86 & -0.97 & -0.12 & -0.68 & 0.42 & -0.63 & -0.01 & -0.63 & -0.21 & -21.08 & -2.33 \\
\hline $\mathrm{I}_{\mathrm{NSG}}$ vs $\mathrm{I}_{\mathrm{GC}}(4741)$ & 0.18 & -0.31 & -0.63 & 0.31 & 0.67 & -0.23 & -0.06 & 0.04 & 0.05 & -0.21 & 30.41 & 8.79 \\
\hline $\mathrm{I}_{\mathrm{SILO}} v s \mathrm{I}_{\mathrm{GC}}(4741)$ & -0.11 & -2.17 & -1.59 & 0.19 & -0.01 & 0.19 & -0.69 & 0.03 & -0.58 & -0.42 & 9.33 & 6.46 \\
\hline \multicolumn{13}{|c|}{ RMSE } \\
\hline SILO vs NSG (370) & 2.70 & 12.19 & 2.62 & 10.02 & 12.03 & 1.28 & 1.28 & 0.16 & 1.67 & 1.28 & 679.85 & 256.89 \\
\hline $\mathrm{I}_{\mathrm{SILO}}$ vs $\mathrm{I}_{\mathrm{NSG}}(4741)$ & 2.71 & 10.67 & 2.96 & 5.42 & 5.82 & 1.16 & 2.08 & 0.21 & 2.18 & 1.63 & 363.23 & 141.70 \\
\hline $\mathrm{I}_{\mathrm{NSG}}$ vs $\mathrm{I}_{\mathrm{GC}}(4741)$ & 3.16 & 13.65 & 3.47 & 6.74 & 6.55 & 1.43 & 2.39 & 0.22 & 2.56 & 1.82 & 443.06 & 168.16 \\
\hline $\mathrm{I}_{\mathrm{SILO}} v s \mathrm{I}_{\mathrm{GC}}(4741)$ & 3.10 & 13.66 & 3.97 & 7.03 & 6.32 & 1.55 & 2.65 & 0.28 & 2.83 & 2.11 & 451.82 & 169.84 \\
\hline \multicolumn{13}{|c|}{ NSE (no units) } \\
\hline SILO vs NSG (370) & 0.90 & 0.89 & 0.93 & 0.90 & 0.88 & 0.90 & 0.96 & 0.93 & 0.95 & 0.93 & 0.91 & 0.91 \\
\hline $\mathrm{I}_{\mathrm{SILO}}$ vs $\mathrm{I}_{\mathrm{NSG}}(4741)$ & 0.84 & 0.85 & 0.90 & 0.90 & 0.89 & 0.86 & 0.88 & 0.89 & 0.89 & 0.85 & 0.90 & 0.91 \\
\hline $\mathrm{I}_{\mathrm{NSG}}$ vs $\mathrm{I}_{\mathrm{GC}}(4741)$ & 0.80 & 0.81 & 0.88 & 0.86 & 0.80 & 0.83 & 0.86 & 0.86 & 0.86 & 0.83 & 0.86 & 0.87 \\
\hline $\mathrm{I}_{\mathrm{SILO}} v s \mathrm{I}_{\mathrm{GC}}(4741)$ & 0.77 & 0.78 & 0.85 & 0.84 & 0.80 & 0.80 & 0.84 & 0.84 & 0.84 & 0.78 & 0.85 & 0.86 \\
\hline
\end{tabular}


Table 4 Variance inflation factor (VIF) for all MBEs in all gridded climate variables and the stepwise regression associated with the 12 key APSIM outputs of wheat cropping system in Murray-Riverina cropping region. The values of the stepwise regression for exclusion of RI or RP are shown, except for the multiple linear regression of CY which shows the exclusion of MBEs of each climate variable. The variables in significant collinearity (mean \pm s.d. over the sites) are in bold. The regression was based on the sites with MBE of each variable $>0$ only.

\begin{tabular}{|c|c|c|c|c|c|c|c|}
\hline Variable & $\begin{array}{l}\text { No of } \\
\text { site }\end{array}$ & Test variables & $T X^{\dagger}$ & $T I$ & $R n$ & $R I$ & $R P$ \\
\hline $\begin{array}{l}\text { Runoff } \\
\text { (RO) }\end{array}$ & 235 & $\begin{array}{c}\text { All } \\
\text { Excl. } R I \\
\text { Excl. } R P \\
\end{array}$ & $\begin{array}{r}\mathbf{2 1 . 9 5} \pm \mathbf{2 0 . 2 3} \\
2.35 \pm 1.49 \\
2.44 \pm 1.37 \\
\end{array}$ & $\begin{array}{r}\mathbf{2 1 . 5 5} \pm \mathbf{2 0 . 6 3} \\
2.40 \pm 1.50 \\
2.49 \pm 1.37 \\
\end{array}$ & $\begin{array}{r}\mathbf{1 6 . 6 6} \pm \mathbf{1 2 . 4 6} \\
1.84 \pm 1.61 \\
1.88 \pm 2.71 \\
\end{array}$ & $\begin{array}{r}\mathbf{1 6 . 6 6} \pm \mathbf{1 2 . 4 6} \\
1.88 \pm 2.71 \\
\end{array}$ & $\begin{array}{r}\mathbf{1 6 . 9 9} \pm \mathbf{1 2 . 4 7} \\
1.70 \pm 1.21\end{array}$ \\
\hline $\begin{array}{l}\text { Deep drainage } \\
\text { (DD) }\end{array}$ & 92 & $\begin{array}{c}\text { All } \\
\text { Excl. RI } \\
\text { Excl. RP }\end{array}$ & $\begin{array}{r}33.53 \pm 39.83 \\
3.35 \pm 1.94 \\
2.64 \pm 1.38 \\
\end{array}$ & $\begin{array}{r}33.53 \pm 39.83 \\
3.35 \pm 1.94 \\
2.64 \pm 1.38 \\
\end{array}$ & $\begin{array}{r}\mathbf{3 0 . 9 6} \pm \mathbf{3 8 . 2 9} \\
8.01 \pm 52.07 \\
2.18 \pm 2.08 \\
\end{array}$ & $\begin{array}{r}30.96 \pm 38.29 \\
2.18 \pm 2.08 \\
\end{array}$ & $\begin{array}{r}31.46 \pm 38.57 \\
2.56 \pm 2.40\end{array}$ \\
\hline $\begin{array}{l}\text { Soil } \\
\text { evaporation } \\
\text { (CES) } \\
\end{array}$ & 253 & $\begin{array}{c}\text { All } \\
\text { Excl. RI } \\
\text { Excl. RP } \\
\end{array}$ & $\begin{array}{r}\mathbf{1 8 . 1 4} \pm \mathbf{1 7 . 9 9} \\
2.33 \pm 1.56 \\
2.11 \pm 1.15 \\
\end{array}$ & $\begin{array}{r}\mathbf{1 7 . 7 7} \pm \mathbf{1 7 . 8 2} \\
2.31 \pm 1.54 \\
2.08 \pm 1.14 \\
\end{array}$ & $\begin{array}{r}\mathbf{1 4 . 5 5} \pm \mathbf{1 1 . 0 6} \\
1.75 \pm 1.49 \\
1.99 \pm 3.86 \\
\end{array}$ & $\begin{array}{r}\mathbf{1 4 . 5 1} \pm \mathbf{1 1 . 0 5} \\
1.99 \pm 3.86 \\
\end{array}$ & $\begin{array}{r}\mathbf{1 4 . 5 6} \pm \mathbf{1 0 . 9 1} \\
1.70 \pm 1.38\end{array}$ \\
\hline $\begin{array}{l}\text { Water uptake } \\
\text { (WU) }\end{array}$ & 233 & $\begin{array}{c}\text { All } \\
\text { Excl. RI } \\
\text { Excl. RP }\end{array}$ & $\begin{array}{r}\mathbf{1 8 . 9 8} \pm \mathbf{1 7 . 9 0} \\
2.48 \pm 1.54 \\
2.47 \pm 1.74 \\
\end{array}$ & $\begin{array}{r}\mathbf{1 8 . 9 8} \pm \mathbf{1 7 . 9 0} \\
2.46 \pm 1.53 \\
2.44 \pm 1.72 \\
\end{array}$ & $\begin{array}{r}\mathbf{1 3 . 9 5} \pm \mathbf{1 0 . 1 2} \\
2.88 \pm \mathbf{1 6 . 6 1} \\
2.25 \pm 4.27 \\
\end{array}$ & $\begin{array}{r}\mathbf{1 3 . 9 5} \pm \mathbf{1 0 . 1 2} \\
2.25 \pm 4.26 \\
\end{array}$ & $\begin{array}{r}\mathbf{1 3 . 9 7} \pm \mathbf{1 0 . 0 1} \\
1.61 \pm 1.20\end{array}$ \\
\hline $\begin{array}{l}\text { N uses } \\
(\mathrm{NU})\end{array}$ & 229 & $\begin{array}{c}\text { All } \\
\text { Excl. RI } \\
\text { Excl. RP }\end{array}$ & $\begin{array}{r}\mathbf{1 8 . 8 2} \pm \mathbf{1 8 . 8 4} \\
2.45 \pm 1.62 \\
2.35 \pm 1.34 \\
\end{array}$ & $\begin{array}{r}\mathbf{1 8 . 8 2} \pm \mathbf{1 8 . 8 4} \\
2.45 \pm 1.62 \\
2.35 \pm 1.34 \\
\end{array}$ & $\begin{array}{r}\mathbf{1 3 . 9 0} \pm \mathbf{1 0 . 0 6} \\
2.01 \pm 5.27 \\
1.78 \pm 2.92 \\
\end{array}$ & $\begin{array}{r}\mathbf{1 3 . 9 0} \pm \mathbf{1 0 . 0 6} \\
1.78 \pm 2.91 \\
\end{array}$ & $\begin{array}{r}\mathbf{1 4 . 1 0} \pm \mathbf{9 . 9 5} \\
1.63 \pm 1.20\end{array}$ \\
\hline $\begin{array}{l}\text { Sowing date } \\
\text { (SD) }\end{array}$ & 44 & $\begin{array}{c}\text { All } \\
\text { Excl. RI } \\
\text { Excl. RP }\end{array}$ & $\begin{array}{r}\mathbf{2 6 . 0 5} \pm \mathbf{2 1 . 3 3} \\
2.64 \pm 2.40 \\
2.74 \pm 2.98 \\
\end{array}$ & $\begin{array}{r}\mathbf{2 6 . 4 7} \pm 21.44 \\
2.65 \pm 2.42 \\
2.74 \pm 3.01 \\
\end{array}$ & $\begin{array}{r}\mathbf{2 6 . 0 5} \pm \mathbf{2 1 . 3 3} \\
2.64 \pm 2.40 \\
2.74 \pm 2.98 \\
\end{array}$ & $\begin{array}{r}26.05 \pm 21.33 \\
2.74 \pm 2.98 \\
\end{array}$ & $\begin{array}{r}26.05 \pm 21.33 \\
2.64 \pm 2.40\end{array}$ \\
\hline $\begin{array}{l}\text { Sowing to } \\
\text { Flowering } \\
\text { (STF) }\end{array}$ & 75 & $\begin{array}{c}\text { All } \\
\text { Excl. RI } \\
\text { Excl. RP }\end{array}$ & $\begin{array}{r}\mathbf{2 2 . 6 8} \pm \mathbf{1 7 . 7 2} \\
2.69 \pm 1.62 \\
2.62 \pm 1.77 \\
\end{array}$ & $\begin{array}{r}\mathbf{2 2 . 6 8} \pm \mathbf{1 7 . 7 2} \\
2.69 \pm 1.62 \\
2.62 \pm 1.77 \\
\end{array}$ & $\begin{array}{r}\mathbf{2 2 . 4 8} \pm \mathbf{1 7 . 6 8} \\
2.69 \pm 1.62 \\
2.62 \pm 1.77 \\
\end{array}$ & $\begin{array}{r}\mathbf{2 2 . 4 8} \pm \mathbf{1 7 . 6 8} \\
2.62 \pm 1.77 \\
\end{array}$ & $\begin{array}{r}\mathbf{2 2 . 4 8} \pm \mathbf{1 7 . 6 8} \\
2.69 \pm 1.62\end{array}$ \\
\hline $\begin{array}{l}\text { Flowering to } \\
\text { harvest } \\
(\mathrm{FTH})\end{array}$ & 32 & $\begin{array}{c}\text { All } \\
\text { Excl. RI } \\
\text { Excl. RP }\end{array}$ & $\begin{array}{r}\mathbf{2 0 . 5 5} \pm \mathbf{1 8 . 0 9} \\
2.81 \pm 1.67 \\
2.99 \pm 2.57 \\
\end{array}$ & $\begin{array}{r}\mathbf{2 0 . 5 5} \pm \mathbf{1 8 . 0 9} \\
2.81 \pm 1.67 \\
2.99 \pm 2.57 \\
\end{array}$ & $\begin{array}{r}\mathbf{2 0 . 5 5} \pm \mathbf{1 8 . 0 9} \\
2.81 \pm 1.67 \\
2.99 \pm 2.57 \\
\end{array}$ & $\begin{array}{r}\mathbf{2 0 . 5 5} \pm \mathbf{1 8 . 0 9} \\
2.99 \pm 2.57 \\
\end{array}$ & $\begin{array}{r}20.55 \pm 18.09 \\
2.81 \pm 1.67\end{array}$ \\
\hline $\begin{array}{l}\text { Crop duration } \\
\text { (CD) }\end{array}$ & 74 & $\begin{array}{c}\text { All } \\
\text { Excl. RI } \\
\text { Excl. RP }\end{array}$ & $\begin{array}{r}\mathbf{2 1 . 6 7} \pm \mathbf{1 8 . 9 7} \\
2.78 \pm 1.71 \\
2.58 \pm 1.84 \\
\end{array}$ & $\begin{array}{r}\mathbf{2 1 . 6 7} \pm \mathbf{1 8 . 9 7} \\
2.78 \pm 1.71 \\
2.58 \pm 1.84 \\
\end{array}$ & $\begin{array}{r}\mathbf{2 1 . 6 7} \pm \mathbf{1 8 . 9 7} \\
2.78 \pm 1.71 \\
2.58 \pm 1.84 \\
\end{array}$ & $\begin{array}{r}\mathbf{2 1 . 6 7} \pm \mathbf{1 8 . 9 7} \\
2.58 \pm 1.84 \\
\end{array}$ & $\begin{array}{r}\mathbf{2 1 . 6 7} \pm \mathbf{1 8 . 9 7} \\
2.78 \pm 1.71\end{array}$ \\
\hline $\begin{array}{l}\text { Harvesting } \\
\text { date } \\
\text { (HD) } \\
\end{array}$ & 69 & $\begin{array}{c}\text { All } \\
\text { Excl. RI } \\
\text { Excl. RP }\end{array}$ & $\begin{array}{r}22.29 \pm 21.92 \\
2.66 \pm 1.64 \\
2.67 \pm 1.95 \\
\end{array}$ & $\begin{array}{r}22.48 \pm 22.04 \\
2.67 \pm 1.65 \\
2.67 \pm 1.96 \\
\end{array}$ & $\begin{array}{r}\mathbf{2 2 . 2 9} \pm \mathbf{2 1 . 9 2} \\
2.66 \pm 1.64 \\
2.67 \pm 1.95 \\
\end{array}$ & $\begin{array}{r}22.29 \pm 21.92 \\
2.67 \pm 1.95 \\
\end{array}$ & $\begin{array}{r}22.29 \pm 21.92 \\
2.66 \pm 1.64\end{array}$ \\
\hline $\begin{array}{l}\text { Biomass } \\
(\mathrm{BM})\end{array}$ & 240 & $\begin{array}{c}\text { All } \\
\text { Excl. RI } \\
\text { Excl. RP }\end{array}$ & $\begin{array}{r}\mathbf{1 8 . 5 6} \pm \mathbf{1 7 . 7 2} \\
2.49 \pm 1.56 \\
2.48 \pm 1.74 \\
\end{array}$ & $\begin{array}{r}\mathbf{1 8 . 5 6} \pm \mathbf{1 7 . 7 2} \\
2.49 \pm 1.56 \\
2.45 \pm 1.72 \\
\end{array}$ & $\begin{array}{r}\mathbf{1 4 . 3 9} \pm \mathbf{1 0 . 1 8} \\
2.63 \pm \mathbf{1 3 . 8 8} \\
2.23 \pm 4.24 \\
\end{array}$ & $\begin{array}{r}\mathbf{1 4 . 3 5} \pm \mathbf{1 0 . 1 7} \\
2.22 \pm 4.23 \\
\end{array}$ & $\begin{array}{r}\mathbf{1 4 . 3 7} \pm \mathbf{1 0 . 0 6} \\
1.61 \pm 1.20\end{array}$ \\
\hline $\begin{array}{l}\text { Crop yield } \\
(\mathrm{CY})\end{array}$ & 237 & $\begin{array}{c}\text { All } \\
\text { Excl. } T X \\
\text { Excl. TI } \\
\text { Excl. Rn } \\
\text { Excl. } R I \\
\text { Excl. RP }\end{array}$ & $\begin{array}{r}\mathbf{1 7 . 5 7} \pm \mathbf{1 7 . 3 9} \\
\mathbf{1 2 . 3 0} \pm \mathbf{6 . 4 1} \\
7.62 \pm 5.42 \\
2.48 \pm 1.58 \\
2.50 \pm 1.76 \\
\end{array}$ & $\begin{array}{r}\mathbf{1 7 . 5 7} \pm \mathbf{1 7 . 3 9} \\
\mathbf{1 4 . 5 9} \pm \mathbf{9 . 0 5} \\
\\
7.46 \pm 5.41 \\
2.46 \pm 1.56 \\
2.47 \pm 1.74 \\
\end{array}$ & $\begin{array}{r}14.01 \pm \mathbf{1 0 . 1 3} \\
13.61 \pm 8.47 \\
13.31 \pm 8.15 \\
\\
2.19 \pm 7.54 \\
2.08 \pm 4.06 \\
\end{array}$ & $\begin{array}{r}\mathbf{1 4 . 0 1} \pm \mathbf{1 0 . 1 3} \\
\mathbf{1 3 . 6 1} \pm \mathbf{8 . 4 7} \\
\mathbf{1 3 . 3 1} \pm \mathbf{8 . 1 5} \\
7.48 \pm 5.52 \\
\\
2.09 \pm 4.05 \\
\end{array}$ & $\begin{array}{r}14.02 \pm 9.98 \\
13.58 \pm 8.17 \\
13.27 \pm 7.82 \\
7.74 \pm 5.31 \\
1.62 \pm 1.21\end{array}$ \\
\hline
\end{tabular}

${ }^{\dagger}$ The test variable means the test whether this variable, e.g., TX, has collinearity with other variables, i.e., TI, Rn, RI and/or RP. 
Table 5 The coefficients and statistics of the multiple linear least squared regression of biases in APSIMsimulated outputs as a function of the bias in climate variables (Eq. 4, without radiation). The mean coefficient and the standard deviation ( \pm s.d.) are shown. The number of these sites with significance $(\mathrm{P}<0.05)$ being greater than $1 / 3$, but less than $2 / 3$ is marked in italics and more than $2 / 3$ in bold. The regression was based on the sites with MBE of each variable $>0$ only.

\begin{tabular}{|c|c|c|c|c|c|c|c|}
\hline Variable & $\begin{array}{l}\text { No of } \\
\text { sites }\end{array}$ & $\begin{array}{l}\mathrm{MBE}_{\mathrm{TX}} \\
\mathrm{b}\left({ }^{\circ} \mathrm{C}^{-1}\right)\end{array}$ & $\begin{array}{l}\mathrm{MBE}_{\mathrm{TI}} \\
\mathrm{c}\left({ }^{\circ} \mathrm{C}^{-1}\right)\end{array}$ & $\begin{array}{c}\mathrm{MBE}_{\mathrm{Rn}} \\
\mathrm{d}\left(\mathrm{mm}^{-1}\right)\end{array}$ & $\begin{array}{c}\mathrm{MBE}_{\mathrm{RI}} \\
\mathrm{e}\left(\left(\mathrm{mm} \mathrm{rain}^{-1}\right)^{-1}\right)\end{array}$ & $\begin{array}{l}\mathrm{MBE}_{\mathrm{RP}} \\
\mathrm{f}\left(\%^{-1}\right)\end{array}$ & $\begin{array}{c}\mathrm{R}^{2} \\
\left(\min \mathrm{R}^{2} \sim \max \mathrm{R}^{2}\right)\end{array}$ \\
\hline $\mathrm{MBE}_{\mathrm{RO}}$ & 235 & $1.37 \pm 2.58$ & $1.33 \pm 4.60$ & $0.09 \pm 0.09$ & & $-0.13 \pm 0.32$ & $0.45 \pm 0.22(0.05 \sim 0.95)$ \\
\hline$(\mathrm{mm})$ & & $1.58 \pm 2.16$ & $0.57 \pm 4.28$ & $0.08 \pm 0.09$ & $0.01 \pm 0.02$ & & $0.45 \pm 0.21(0.05 \sim 0.97)$ \\
\hline $\mathrm{MBE}_{\mathrm{DD}}$ & 92 & $-10.46 \pm 52.91$ & $0.27 \pm 48.52$ & $0.62 \pm 0.32$ & & $0.08 \pm 1.74$ & $0.76 \pm 0.18(0.20 \sim 1.00)$ \\
\hline$(\mathrm{mm})$ & & $-6.74 \pm 45.73$ & $1.16 \pm 54.80$ & $0.64 \pm 0.30$ & $-0.01 \pm 0.11$ & & $0.75 \pm 0.19(0.19 \sim 1.00)$ \\
\hline $\mathrm{MBE}_{\mathrm{CES}}$ & 253 & $0.70 \pm 11.50$ & $1.89 \pm 10.53$ & $0.10 \pm 0.15$ & & $0.27 \pm 0.29$ & $0.49 \pm 0.23(0.07 \sim 0.98)$ \\
\hline$(\mathrm{mm})$ & & $1.05 \pm 11.02$ & $2.79 \pm 11.73$ & $0.12 \pm 0.16$ & $-0.01 \pm 0.03$ & & $0.49 \pm 0.23(0.05 \sim 0.98)$ \\
\hline $\mathrm{MBE}_{\mathrm{WU}}$ & 233 & $4.48 \pm 24.23$ & $-8.89 \pm 21.81$ & $0.21 \pm 0.32$ & & $-0.09 \pm 1.16$ & $0.47 \pm 0.21(0.01 \sim 1.00)$ \\
\hline$(\mathrm{mm})$ & & $2.81 \pm 21.50$ & $-10.60 \pm 29.65$ & $0.17 \pm 0.35$ & $0.02 \pm 0.10$ & & $0.47 \pm 0.21(0.01 \sim 1.00)$ \\
\hline $\mathrm{MBE}_{\mathrm{NU}}$ & 229 & $0.55 \pm 29.26$ & $-7.75 \pm 30.19$ & $0.10 \pm 0.20$ & & $0.02 \pm 1.29$ & $0.38 \pm 0.21(0.01 \sim 0.99)$ \\
\hline$\left(\mathrm{kg} \mathrm{ha}^{-1}\right)$ & & $0.58 \pm 28.87$ & $-10.45 \pm 38.94$ & $0.09 \pm 0.24$ & $0.00 \pm 0.08$ & & $0.38 \pm 0.21(0.01 \sim 0.99)$ \\
\hline $\mathrm{MBE}_{\mathrm{SD}}$ & 44 & $13.81 \pm 32.84$ & $19.22 \pm 48.56$ & $-0.07 \pm 0.14$ & & $0.07 \pm 0.46$ & $0.92 \pm 0.06(0.69 \sim 1.00)$ \\
\hline (doy) & & $12.94 \pm 31.15$ & $20.56 \pm 45.24$ & $-0.06 \pm 0.16$ & $0.01 \pm 0.03$ & & $0.92 \pm 0.06(0.69 \sim 1.00)$ \\
\hline $\mathrm{MBE}_{\mathrm{STF}}$ & 75 & $-9.50 \pm 12.45$ & $-6.03 \pm 18.65$ & $0.03 \pm 0.08$ & & $-0.07 \pm 0.37$ & $0.91 \pm 0.07$ (0.65 0.99) \\
\hline (days) & & $-9.27 \pm 11.84$ & $-6.50 \pm 17.58$ & $0.04 \pm 0.10$ & $-0.01 \pm 0.03$ & & $0.91 \pm 0.07(0.65 \sim 0.99)$ \\
\hline $\mathrm{MBE}_{\mathrm{FTH}}$ & 32 & $-2.03 \pm 3.61$ & $-1.21 \pm 5.05$ & $0.01 \pm 0.03$ & & $-0.03 \pm 0.14$ & $0.72 \pm 0.20(0.14 \sim 0.97)$ \\
\hline (days) & & $-1.95 \pm 3.74$ & $-1.61 \pm 5.03$ & $0.01 \pm 0.04$ & $0.00 \pm 0.01$ & & $0.71 \pm 0.20(0.15 \sim 0.97)$ \\
\hline $\mathrm{MBE}_{\mathrm{CD}}$ & 74 & $-12.21 \pm 25.54$ & $-3.97 \pm 40.81$ & $0.08 \pm 0.20$ & & $-0.06 \pm 0.49$ & $0.91 \pm 0.10(0.24 \sim 0.99)$ \\
\hline (Days) & & $-11.47 \pm 24.30$ & $-4.97 \pm 36.48$ & $0.08 \pm 0.21$ & $-0.01 \pm 0.04$ & & $0.91 \pm 0.10(0.24 \sim 0.99)$ \\
\hline $\mathrm{MBE}_{\mathrm{HD}}$ & 69 & $7.68 \pm 9.22$ & $2.11 \pm 11.00$ & $-0.01 \pm 0.12$ & & $-0.01 \pm 0.47$ & $0.84 \pm 0.12(0.44 \sim 1.00)$ \\
\hline (doy) & & $7.66 \pm 8.40$ & $1.61 \pm 9.64$ & $-0.01 \pm 0.13$ & $0.01 \pm 0.03$ & & $0.85 \pm 0.11(0.51 \sim 1.00)$ \\
\hline $\mathrm{MBE}_{\mathrm{BM}}$ & 240 & $-513.97 \pm 1573.93$ & $-541.20 \pm 1669.48$ & $14.41 \pm 22.32$ & & $-5.22 \pm 77.34$ & $0.47 \pm 0.22(0.02 \sim 1.00)$ \\
\hline$\left(\mathrm{kg} \mathrm{ha}^{-1}\right)$ & & $-559.93 \pm 1415.69$ & $-664.98 \pm 2183.55$ & $12.75 \pm 24.07$ & $0.67 \pm 6.11$ & & $0.48 \pm 0.22(0.02 \sim 1.00)$ \\
\hline $\mathrm{MBE}_{\mathrm{CY}}$ & 237 & $-137.41 \pm 578.63$ & $-129.92 \pm 544.37$ & $5.84 \pm 8.67$ & & $-0.64 \pm 30.64$ & $0.46 \pm 0.22(0.01 \sim 0.99)$ \\
\hline$\left(\mathrm{kg} \mathrm{ha}^{-1}\right)$ & & $-150.53 \pm 518.99$ & $-157.16 \pm 710.37$ & $5.62 \pm 9.21$ & $0.11 \pm 2.18$ & & $0.47 \pm 0.22(0.01 \sim 0.99)$ \\
\hline
\end{tabular}


Table 2: Statistical tests of the differences between the interpolated and observed climate variables and the differences between the spatial interpolated values in each pair of these based on site observations, the sitelocated grids and the 5-km grids in the growing season period.

\begin{tabular}{lrrrrrrr}
\hline \multicolumn{1}{c}{ Data source } & no & $\begin{array}{r}\text { SR } \\
\left(\mathrm{MJ} \mathrm{m}^{-2}\right)\end{array}$ & $\begin{array}{r}\mathrm{TX} \\
\left({ }^{\circ} \mathrm{C}\right)\end{array}$ & $\begin{array}{r}\mathrm{TI} \\
\left({ }^{\circ} \mathrm{C}\right)\end{array}$ & $\begin{array}{r}\mathrm{Rn} \\
(\mathrm{mm})\end{array}$ & $\begin{array}{r}\mathrm{RI} \\
\left(\mathrm{mm} \mathrm{rn}^{-1}\right)\end{array}$ & $\begin{array}{r}\mathrm{RP} \\
(\%)\end{array}$ \\
\hline SILO vs NSG & 370 & 0.00 & 0.00 & 0.00 & -2.56 & 0.63 & -3.46 \\
SILO vs NSG & 4741 & 0.00 & 0.00 & 0.00 & -1.41 & 0.80 & -2.92 \\
NSG vs GC & 4741 & 0.00 & 0.04 & 0.03 & -0.67 & 0.38 & -2.02 \\
SILO vs GC & 4741 & 0.00 & 0.04 & 0.02 & -2.07 & 1.18 & -4.94 \\
& & \multicolumn{7}{c}{ RMSE } \\
SILO vs NSG & 370 & 0.08 & 0.12 & 0.09 & 15.06 & 0.88 & 4.67 \\
SILO vs NSG & 4741 & 0.01 & 0.10 & 0.07 & 10.27 & 0.94 & 3.43 \\
NSG vs GC & 4741 & 0.04 & 0.35 & 0.22 & 26.47 & 0.49 & 2.44 \\
SILO vs GC & 4741 & 0.04 & 0.36 & 0.24 & 26.70 & 1.33 & 5.50 \\
& & \multicolumn{7}{c}{ NSE (no units) } & & & \\
SILO vs NSG & 370 & 0.88 & 0.97 & 0.96 & 0.94 & 0.40 & 0.39 \\
SILO vs NSG & 4741 & 1.00 & 0.99 & 0.98 & 0.96 & 0.03 & 0.24 \\
NSG vs GC & 4741 & 0.92 & 0.82 & 0.86 & 0.89 & 0.34 & 0.47 \\
SILO vs GC & 4741 & 0.92 & 0.82 & 0.85 & 0.88 & -0.43 & -0.30 \\
\hline
\end{tabular}




\section{University Library}

\section{- M M N E R VA A gateway to Melbourne's research publications}

Minerva Access is the Institutional Repository of The University of Melbourne

Author/s:

Liu, DL;Ji, F;Wang, B;Waters, C;Feng, P;Darbyshire, R

Title:

The implication of spatial interpolated climate data on biophysical modelling in agricultural systems

Date:

2019-12-17

Citation:

Liu, D. L., Ji, F., Wang, B., Waters, C., Feng, P. \& Darbyshire, R. (2019). The implication of spatial interpolated climate data on biophysical modelling in agricultural systems. INTERNATIONAL JOURNAL OF CLIMATOLOGY, 40 (5), pp.2870-2890. https:// doi.org/10.1002/joc.6371.

Persistent Link:

http://hdl.handle.net/11343/286753 